\title{
Development of a Hydrochloric Acid Process for the Production of Alumina from Clay
}

\section{By James I. Hoffman, Robert T. Leslie, Harold J. Caul,* Lewis Jesse Clark, and John Drake Hoffman}

\begin{abstract}
The development of a process for the extraction of alumina from clay and the construction of a pilot plant are described.

The process consists in (1) roasting clay at about $700^{\circ} \mathrm{C}$, (2) digesting the roasted product with dilute hydrochloric acid, (3) filtering to separate the insoluble siliceous matter from the solution containing the aluminum and soluble impurities, such as iron and alkali salts, (4) concentrating the solution, (5) precipitating the aluminum as the hydrated chloride from the concentrated solution by adding hydrochloric acid gas, (6) removing the crystals of hydrated aluminum chloride, (7) washing the crystals to remove adhering impurities, (8) calcining the hydrated chloride to obtain alumina, and (9) recovering hydrochloric acid from the waste products at the end of the process.

The operation of the pilot plant shows that the process is feasible for the production of alumina from clay but that the alumina costs more than that produced from bauxite by the present well-known processes.
\end{abstract}

\section{Introduction}

The aluminum industry in this country depends to a considerable extent upon bauxite shipped by sea. Shortly after the United States declared war in 1941, submarine warfare seriously interfered with these shipments, and it became important to utilize domestic sources of alumina, of which clay is the most abundant. At a conference in the spring of 1942 between Under Secretary of War Robert P. Patterson, Assistant Attorney General Francis M. Shea, General Brehon Somervell, Joseph Y. Houghton of the Department of Justice, Lymah J. Briggs, Director of the National Bureau of Standards, and James I. Hoffman, it was decided to construct and to operate a pilot plant at the National Bureau of Standards for the extraction of alumina from clay. The first part of the

E.*American Dental Association.

\section{Contents}

I. Introduction _.

II. Clays used in the pilot plant. . . . . . . 411

III. Roasting of the clays_..._._. 412

IV. Decomposition of the clays_..... 414

V. Separation of silica and other insoluble material by filtration....... 416

VI. Concentration of filtrate and washings _.... 417

VII. Precipitation of aluminum chloride, $\mathrm{AlCl}_{3} 6 \mathrm{H}_{2} \mathrm{O} 418$

VIII. Filtration of aluminum chloride_._. _..... 421

IX. Conversion of aluminum chloride to aluminum oxide and recovery of the resulting acid_... 421

X. Properties of the alumina produced _....... 424

XI. Cost of the alumina produced _...

XII. Special equipment_._._._._._._. 426

XIII. Summary and conclusions _. _............. 427 
work was done with War Department funds. Lt. Col. Henry M. Huxley acted as liaison officer between the War Department and the Bureau during the early part of the construction, and Capt. Robert Banks acted in the same role during: the latter part of construction and operation. Both of these officers deserve much credit for their cooperation and helpful suggestions.

Preliminary plans for the plant were started in May 1942, but owing to extreme difficulty in obtaining delivery of equipment, actual construction could not be started until about January 1, 1943. On May 15, 1943, limited operation of the plant started, and on May 25, 1943, the first satisfactory alumina was produced. For the 2 years following, the plant was in almost continuous operation, with only occasional shut-downs for improvements and repairs.

The process consists in (1) roasting clay at about $700^{\circ} \mathrm{C}$, (2) digesting the roasted product in dilute hydrochloric acid, (3) filtering to separate the insoluble siliceous matter from the solution containing the aluminum and soluble impurities such as iron and alkali salts, (4) concentrating the solution, (5) precipitating the aluminum as the hydrated chloride from the concentrated solution by adding hydrochloric acid gas, (6) removing the crystals of hydrated aluminum chloride,

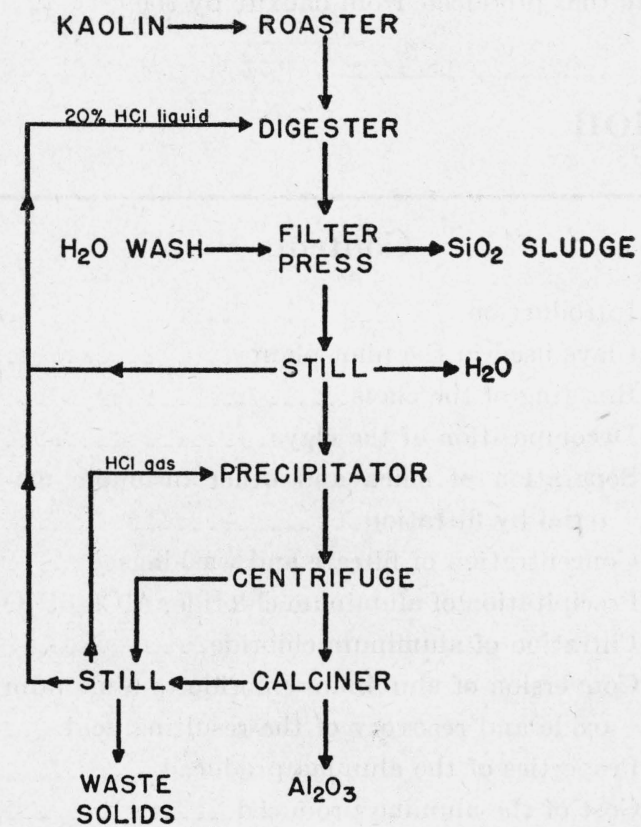

Figdre 1.-Simplified flow-sheet of Hoffman alumina process. washing the crystals to remove adhering impurities, (8) calcining the hydrated chloride to obtain alumina, and (9) recovering hydrochloric acid from the waste products at the end of the process.

The process in simplified form is outlined on the flow sheet, figure 1.

The preliminary experimental work centered around two main problems: (1) decomposition of clay with hydrochloric acid and (2) efficient separation of aluminum from iron and other soluble constituents of the clay. The alumina can be dissolved out of all clays by treatment with hydrochloric acid in closed containers at $300^{\circ} \mathrm{C},{ }^{1}$ but the high pressures developed rendered this type of decomposition unsuitable for plant installations with the equipment available. Roasting the clay at about $700^{\circ} \mathrm{C}$, according to the work of $\mathrm{G}$. S. Tilley, A. W. Millar, and O. C. Ralston, ${ }^{2}$ made it possible to dissolve the alumina in most clays at atmospheric pressure with dilute hydrochloric acid at approximately $100^{\circ} \mathrm{C}$. The roasting procedure was therefore adopted so that the clay could be decomposed at atmospheric pressure.

For the separation of aluminum from iron and other constituents of clay that are soluble in hydrochloric acid, some procedure involving precipitation of hydrated aluminum chloride seemed best. By saturating a cool hydrochloric acid solution of the soluble constituents of clay with hydrochloric acid gas, only aluminum chloride hexahydrate, $\mathrm{AlCl}_{3} .6 \mathrm{H}_{2} \mathrm{O}$, is precipitated. ${ }^{3}$ Practically all the other constituents remain in solution. This is in contrast with the separation of iron by extraction with ether, whereby only part of the iron is removed, and practically all other impurities remain with the aluminum. ${ }^{4}$

Instead of saturating the solution with hydrochloric acid gas to precipitate aluminum chloride, the aluminum can be separated as the chloride by partial evaporation. The aluminum chloride crystals thus formed have about the same solublityi in the hot solution as in the cold, and laboratory

\footnotetext{
1 Edward Wichers, William G. Schlecht, and Charles L. Gordon, Preparing refractory oxides, silicates, and ceramic materials for analysis, by heating with acids in sealed tubes at elevated temperatures, J. Research NBS 33, 451 (1944) RP1621. A process based on decomposition at $250^{\circ}$ to $300^{\circ} \mathrm{C}$ has many attractive features if the difficulties concerning he high pre res can be overcome.

2 U. S. Bur. Mines Bul. 267, Acid processes for the extraction of alumina (1927).

8 F. A. Gooch and F. S. Havens, Am. J. Sci. [4] 2, 416 (1896).

4 G. E. F. Lundell, J. I. Hoffman, and H. A. Bright, Chemical analysis of iron and steel, p. 41 and 347 , J. Wiley \& Sons, New York, N. Y. (1931); J. W. Rothe, Stahl u. Eisen 12, 1052 (1892).
} 
experiments showed that a continuous process can be based on crystallizing followed by centrifuging. ${ }^{5}$ Such a process was contemplated early in the work, but as no suitable crystallizer could be bought from the manufacturers or constructed with the materials then available, it was decided to study first the precipitation of aluminum chloride by addition of hydrochloric acid gas, reserving the process involving crystallizing and centrifuging until a suitable crystallizer could be bought or constructed.

Recovery of hydrochloric acid by fractional distillation is by no means a new process, but it was found that the behavior of solutions of

5 In the analysis of certain ceramic materials, from 1937-1942, the major portion of the alumina was separated from solutions containing comparatively small quantities of iron, lithium, and beryllium by evaporating the solution and then freeing the crystals from mother liquor by decanting and centrifug. ing. (Unpublished work of G. E. F. Lundell and James I. Hoffman at the National Bureau of Standards.) aluminum chloride in dilute hydrochloric acid differs markedly from that of a mixutre containing only water and hydrochloric acid. The ignition of aluminum chloride, sulfate, or nitrate to the oxide is common practice in the chemical laboratory and has never given analysts much difficulty. The process outlined in this discussion therefore does not involve new and mysterious reactions. In fact, the basic reactions involved in this process as well as in those pertaining to other acid processes for the extraction of alumina from clay, had been used and studied at the National Bureau of Standards in the analysis of bauxite, high-alumina refractories, aluminum metal, miscellaneous ceramic materials, and in the redetermination of the atomic weight of aluminum. ${ }^{6}$

6 G. E. F. Lundell and James I. Hoffman, Analysis of bauxite and of refractories of high alumina content, BS J. Research 1, 91 (1928) RP5; Redetermination of the atomic weight of aluminum, J. Research NBS 18, 1 (1937) RP957.

\section{Clays Used in the Pilot Plant}

Experiments in the laboratory indicated that the process is applicable to nearly all clays, although rather incomplete extraction of alumina results in the case of diaspore clay or clays containing high percentages of minerals, such as muscovite. Because of its abundance and accessibility, kaolin seemed to be the best raw material to use. Accordingly, the four kaolins described below were used in all the work in the pilot plant.

Pioneer crude kaolin.-This is a crude kaolin, selected for reasonable freedom from ferruginous material or other impurities that might cause objectionable effects in ceramic products. At present this material is regularly furnished to the ceramic industry but is also available for the manufacture of alumina.

Air-floated kaolin.-Crude kaolin relatively free from mica and grit was crushed in a rotary crusher so that none of the pieces was larger than 1 inch by 3 inches. These were dried in a rotary drier until they contained about 10 percent of free moisture, after which the lumps were crushed in a roller mill, and the drying was almost instantaneously completed with hot air. The crushed material was then projected into a controlled upward stream of air. The finer parts were blown upward, whereas the coarser parts either fell back into the crushing zone or into a separate exit for "rejects". The finer material thus constituted the air-floated kaolin.

Roller-mill rejects.-The roller-mill rejects were the coarser particles mentioned above and can be regarded as a byproduct of the air-floating process.

North Carolina surface kaolin.-The "surface kaolin" was obtained under our direction by Raymond E. Mothershead, of the National Bureau of Standards, from deposits near the surface in the vicinity of Raleigh, N. C. This type of material is entirely unfit for use in the paper or ceramic industry, but might be used under certain conditions to produce alumina. This kaolin was ground and sieved at the Bureau; no part of it was rejected. It should be noted that this surface kaolin is not typical of the regular North Carolina deposits. Samples taken 5 to 6 feet below the surface showed about the same composition as the pioneer crude.

Pioneer crude kaolin, air-floated kaolin, and roller mill rejects were furnished by Edward J. Grassmann, president of the Georgia Kaolin Co., Dry Branch, Ga.

Petrographic examinations of the four kaolins by H. F. McMurdie, Division of Clay and Silicate Products, National Bureau of Standards, showed that pioneer crude, air-floated, and roller-mill rejects contained a small percentage of muscovite, 
which is practically insoluble in dilute hydrochloric acid. A much larger percentage was found in the surface kaolin. The air-floated kaolin had a maximum particle size of about 20 microns, whereas the other three contained much larger grains (up to 200 microns).

Measurements of bulk densities of the kaolins were made to supply information on storage space. The values recorded were obtained by heaping a can $12 \frac{1}{2}$ inches high by 12 inches in diameter with kaolin, tapping lightly with a stick, raking the excess off the top with a straight lath, and then weighing. Such values will vary with the operator, but as all the determinations were made by the same person, the results shown in table 1 give information on comparative volumes of the different types.

TABLE 1.-Bulk densities of the kaolins

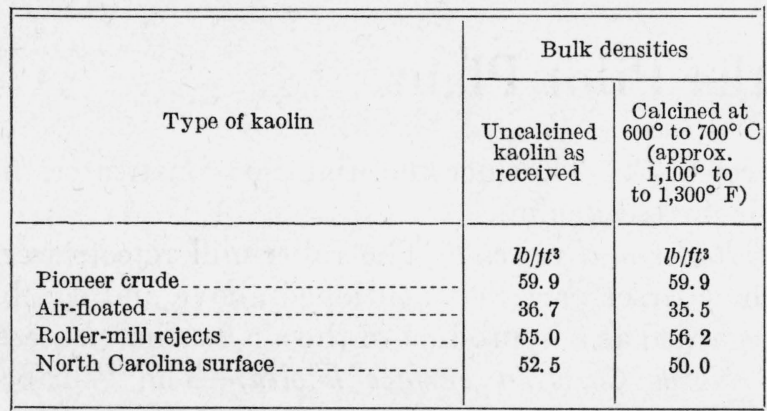

The compositions of the four kaolins are shown in table 2. The results are given on the basis of the material as received.

Chemical analysis showed that all the kaolins contained $\mathrm{ZrO}_{2}$, but that the amount did not exceed 0.1 percent. An important fact is that practically no titania is dissolved out of the calcined clay by any of the dilute acids mentioned. The maximum solubility observed was 0.03 percent with sulfuric, 0.025 percent with hydrochloric, and 0.01 percent with nitric acid.

The chemical analyses were made by Leo Schubert, National Bureau of Standards.

Qualitative spectrochemical analysis by Harold R. Mullin showed that all the kaolins contained minor quantities (between 0.01 and 1 percent) of $\mathrm{Ba}, \mathrm{Cr}, \mathrm{Li}$, and $\mathrm{V}$, and traces (less than 0.01 percent) of $\mathrm{B}, \mathrm{Co}, \mathrm{Cu}, \mathrm{Mn}, \mathrm{Ni}, \mathrm{Pb}, \mathrm{Sc}, \mathrm{Sn}, \mathrm{Sr}, \mathrm{Y}$, and $\mathrm{Zn}$.

TABLE 2.-Composition of kaolins

\begin{tabular}{|c|c|c|c|c|}
\hline Constituent & $\begin{array}{l}\text { Roller- } \\
\text { mill re- } \\
\text { jects }\end{array}$ & $\begin{array}{l}\text { Pioneer } \\
\text { crude }\end{array}$ & $\begin{array}{c}\text { Air- } \\
\text { floated }\end{array}$ & $\begin{array}{l}\text { North } \\
\text { Carolina } \\
\text { surface }\end{array}$ \\
\hline Loss at $110^{\circ} \mathrm{C}_{\ldots} \ldots$ & $\begin{array}{r}\text { Percent } \\
1.84\end{array}$ & $\begin{array}{r}\text { Percent } \\
1.89\end{array}$ & $\begin{array}{c}\text { Percent } \\
0.74\end{array}$ & $\begin{array}{r}\text { Percent } \\
1.03\end{array}$ \\
\hline Loss at $1,200^{\circ} \mathrm{C}$ & 14.3 & 15.0 & 14.4 & 7. 7 \\
\hline Silica $\left(\mathrm{SiO}_{2}\right)_{\ldots} \ldots \ldots$ & 44.9 & 45.1 & 45.0 & 62.1 \\
\hline Aluminum oxide $\left(\mathrm{Al}_{2} \mathrm{O}_{3}\right)$, total & 36.0 & 36.8 & 38.4 & 24.8 \\
\hline Available $\mathrm{Al}_{2} \mathrm{O}_{3}$ & 32.6 & 35.7 & 37.9 & 15.6 \\
\hline Ferric oxide $\left(\mathrm{Fe}_{2} \mathrm{O}_{3}\right)$ & 1.0 & .61 & .43 & .93 \\
\hline Titanium dioxide $\left(\mathrm{TiO}_{2}\right)_{\ldots} \ldots$ & 1.9 & 1.4 & 1.4 & 1.1 \\
\hline Phosphoric anhydride $\left(\mathrm{P}_{2} \mathrm{O}_{5}\right)$ & .03 & .03 & .002 & .001 \\
\hline Calcium oxide $(\mathrm{CaO})$ & .25 & .24 & .06 & .20 \\
\hline Magnesium oxide $(\mathrm{MgO})$ & .26 & .20 & .05 & .22 \\
\hline Sodium oxide $\left(\mathrm{Na}_{2} \mathrm{O}\right)$ & .14 & .07 & .10 & .44 \\
\hline Potassium oxide $\left(\mathrm{K}_{2} \mathrm{O}\right) \ldots$ & .62 & .14 & .07 & 2. 03 \\
\hline
\end{tabular}

a Available alumina is determined as follows: Ignite $5.00 \mathrm{~g}$ of the sample at $700^{\circ} \pm 50^{\circ} \mathrm{C}$ for $1 / 2$ hour. Cool the residue, transfer it to a flask having a capacity of 100 to $200 \mathrm{ml}$, add $50 \mathrm{ml}$ of diluted hydrochloric acid (1 volume of $\mathrm{HCl}$ ap gr $1.18+1$ volume of $\mathrm{H}_{2} \mathrm{O}$ ), cover the flask with a watch glass, and heat at about $100^{\circ} \mathrm{C}$ for 3 hours. Swirl the flask to stir up its contents every 10 minutes. Filter, wash the insoluble residue with water, and determine the alumina in the filtrate and washings. Substantially the same result for available alumina is obtained by the use of diluted sulfuric acid (1 volume of $\mathrm{H}_{2} \mathrm{SO}_{4} \mathrm{sp}$ gr $1.84+3$ volumes of $\mathrm{H}_{2} \mathrm{O}$ ) or diluted nitric acid (1 volume of $\mathrm{HNO}_{2}$ sp gr $1.42+1$ volume of $\mathrm{H}_{2} \mathrm{O}$ ).

\section{Roasting of the Clays}

Roasting to increase the solubility of the alumina in clay has been summarized by G. S. Tilley, R. W. Millar, and O. C. Ralston. ${ }^{7}$ No extended research on roasting was done in the present work, but a few interesting observations will be recorded.

It can be said, in general, that the alumina in clays becomes more soluble in dilute acid $(\mathrm{HCl}$, $\mathrm{HNO}_{3}$, or $\mathrm{H}_{2} \mathrm{SO}_{4}$ ) if the clay is heated for a short period at $700^{\circ} \pm 100^{\circ} \mathrm{C}$ before treatment with the

\footnotetext{
7 U. S. Bur. Mines Bul. 267 (1927).
}

acid. No particular advantage accrues from heating longer than one-quarter hour, nor is any harm done if the heating is prolonged to 1 hour. The wide range in temperature, $\left( \pm 100^{\circ} \mathrm{C}\right)$ is given because the most desirable temperature varies with different clays. Heating at too high a temperature, say $900^{\circ}$ to $1,000^{\circ} \mathrm{C}$, permanently renders the alumina insoluble in dilute hydrochloric acid. In practical work it is advantageous to determine the temperature at which best decomposition occurs for a given material. 
It should be understood that in this discussion interest centers on the total alumina in clays and on the percentage of that alumina that can be dissolved in dilute acids near the boiling point at atmospheric pressure. Most of the work on this project was done with Georgia kaolin from which practically all the alumina can be thus extracted after roasting at $700^{\circ} \mathrm{C}$. However, in preliminary work in the laboratory with two samples of diaspore clay (one from Missouri, the other from Pennsylvania) only about one-half of the alumina could be extracted by treatment with dilute hydrochloric or sulfuric acid at atmospheric pressure, regardless of time or temperature of roasting. Petrographic examinations of these samples showed two distinct mineral species, present in approximately the same ratio as the soluble and insoluble alumina. It is probable that the soluble portion was kaolin and the insoluble portion was diaspore. Diaspore, with or without roasting, can be decomposed by treatment with hydrochloric acid in a closed container at $300^{\circ} \mathrm{C} .^{8}$

Examination of about 15 clays showed that all contained a small quantity of alumina that does not respond to acid attack at atmospheric pressure after roasting. Nearly pure kaolin showed the best response, and the two diaspore clays mentioned, the poorest. Kaolin containing considerable quantities of muscovite occupied a middle position (see North Carolina surface kaolin, table 2). It is evident, therefore, that the nature of the raw material, as well as the roasting procedure and the digestion with acid, must be considered.

Unroasted kaolin containing about 1 percent of ferric oxide is nearly white. On roasting, it progressively becomes darker, up to a temperature in the neighborhood of $700^{\circ} \mathrm{C}$, and then, on heating at increasing temperature, the light-brown color starts to fade. At $1,000^{\circ} \mathrm{C}$ the product is again nearly white. It is in the range of the maximum brown color that the best decomposition results on digestion with acid. This criterion serves in many cases as a practical means of telling whether the kaolin has been properly heated, but observation of the change in color cannot be substituted for a pyrometer because highly colored materials may not follow the rule.

If the roasting is properly done, all but about

\footnotetext{
S Charles L. Gordon, William G. Schlecht, and Edward Wichers, J. Research NBS 33, 457 (1944) RP1622.
}

0.5 percent of the water is driven off. Tests on five kaolins roasted at $700^{\circ} \mathrm{C}$ indicated an additional loss of only 0.4 to 0.5 percent on ignition at $1,200^{\circ} \mathrm{C}$.

If the water of the kaolin is not reduced to 0.5 percent or less in the roasting process, recovery of alumina by digestion with dilute acid is quite unsatisfactory. For example, a sample of improperly roasted kaolin which retained 3.8 percent of its original water yielded 32.3 percent of alumina when treated with dilute hydrochloric acid, whereas a portion of the same kaolin by the same acid treatment yielded 37.8 percent of alumina after it was reroasted at $700^{\circ} \mathrm{C}$ to reduce its water content to 0.5 percent or less. A kaolin once properly roasted does not revert to its original insoluble form in a reasonably short time if it again comes in contact with water. For example, a 5-g portion of pioneer crude kaolin roasted at $700^{\circ} \mathrm{C}$ yielded $1.786 \mathrm{~g}$ of available alumina. A similarly roasted portion of the same kaolin was soaked in water for 4 days, then dried at $110^{\circ} \mathrm{C}$, and similarly treated with dilute hydrochloric acid. The yield of alumina was $1.790 \mathrm{~g}$. The difference in the quantity of alumina dissolved, of course, is insignificant, and similar results were obtained with other kaolins. The roasted kaolin, after soaking with water 4 days, retained 3.5 percent of water when dried at $110^{\circ} \mathrm{C}$. This reabsorbed water, althougb retained at $110^{\circ} \mathrm{C}$, did not decrease the amount of alumina extracted, whereas a decided decrease in soluble alumina resulted from incomplete removal of the original water of constitution. Thus two samples of roasted kaolin might each show 3.5 percent of water. One might have been improperly roasted so that this amount of its original water remained. The other might have been properly roasted at $700^{\circ} \mathrm{C}$ to remove all of its original water and then have been exposed so that it picked up 3.5 percent of moisture. The one retaining its original water of constitution would show the lower percentage of available alumina.

In the pilot plant a three-hearth Wedge furnace was used for the roasting. The hearths were 2 feet 3 inches in diameter by 9 inches in height, inside dimensions. The total roasting area of the three hearths was 10 square feet. The furnace was similar in its general construction and operation to the Nichols Herreshoff furnace shown in figure 7 , except that the flame in the Wedge furnace was 
in direct contact with the kaolin, whereas the Nichols Herreshoff furnace is muffle-fired. The Wedge furnace ${ }^{9}$. was obtained from the Bethlehem Foundry \& Machine Co., Bethlehem, Pa. The usual type of rotary kiln would probably serve equally well.

The center shaft and rabble arms were made of cast iron and were cooled in the conventional way by forcing a stream of cool air through the shaft and arms. The rabble teeth were also made of cast iron. The kaolin used required roasting at about $700^{\circ} \mathrm{C}\left(1290^{\circ} \mathrm{F}\right)$ for best extraction of the alumina with acid. With the heat necessary to maintain the kaolin at this temperature, the castiron rabble arms had a tendency to sag and cause breakages. If this type of furnace is to be used in large installations, the rabble arms and bolts, and possibly the center shaft, should be of rugged construction or be made of metal that will not warp or sag.

The rate of passage of kaolin through the furnace can be controlled by the speed of the rabble arms, provided that a supply of kaolin is always available at the intake at the top of the furnace. An electric vibrating feeder ${ }^{10}$ was used to insure a continuous flow and operated satisfactorily with the pioneer crude, the roller-mill rejects, and the North Carolina surface kaolin. It failed occasionally with the air-floated kaolin because this fluffy type of material packed and would not fall out of the feeding hopper into the furnace. With a large hopper and larger openings, this packing could not stop the flow. No particular significance is to be attached to this difficulty because air-floated

This type of furnace is described by Andrew M. Fairlie in "Sulfuric acid manufacture" (Reinhold Publishing Corporation, New York. N. Y., 1936) and will, therefore, not be described in detail here.

10 Purchased from the Syntron Co., Baltimore, Md. kaolin is not likely to be used in this process on a commercial scale.

The rate of output of calcined clay per hour which generally resulted in the highest percentage of available alumina was as follows for the threehearth furnace described: Air-floated, $25 \mathrm{lb}$; pioneer crude, $60 \mathrm{lb}$; roller-mill rejects, $60 \mathrm{lb}$; and North Carolina surface kaolin, $55 \mathrm{lb}$. At the maximum speed of the rabble mechanism, the output per hour was: air-floated, $50 \mathrm{lb}$; pioneer crude, 100 to $120 \mathrm{lb}$; roller-mill rejects, 100 to $120 \mathrm{lb}$; and North Carolina surface kaolin, $100 \mathrm{lb}$ :

In many cases the roasting did not reduce the combined water to 0.5 percent or less, and consequently complete extraction of the alumina was not possible. Three ways of attaining better dehydration are open, namely, (1) increasing the temperature, (2) decreasing the rate of feeding the kaolin, or (3) increasing the number of hearths of the furnace. Slow feeding aids the dehydration but limits the output. Changing from a threehearth to a six-hearth furnace undoubtedly results in an improvement of the calcined product. For example, a $200-1 b$ portion of kaolin that had been calcined at an average temperature of $1,220^{\circ} \mathrm{F}$ was recalcined at an average temperature of $1,210^{\circ} \mathrm{F}$. There was an additional loss of 2.2 percent of water, and the soluble alumina was increased by 4 percent (from 25.3 to 29.3 percent). Experience, therefore, indicates that, if a furnace of the Wedge type is to be used, it should be constructed with metal or ceramic parts that do not warp or sag if operated at 1,300 to $1,400^{\circ} \mathrm{F}$, and that it should contain six hearths so that slow feeding need not retard the output.

The heat required for proper roasting was approximately $1,690 \mathrm{Btu} / \mathrm{lb}$ of roasted kaolin.

\section{Decomposition of the Clays}

After roasting the kaolin at about $1,300^{\circ} \mathrm{F}$, it was digested at $212^{\circ}$ to $220^{\circ} \mathrm{F}$ with hydrochloric acid, sp gr 1.07 to 1.10 , for about 3 hours. The digester was made of Haveg $41,{ }^{11}$ and is illustrated in figure 2.

The stirrer, $A$, shown in the figure had a blade, $G, 24$ by $3 \frac{1}{2}$ inches, and was driven by a totally

\footnotetext{
${ }^{11}$ Haveg 41 is molded from a mixture of a special acid-digested asbestos and a synthetic phenolformaldehyde resin. It is manufactured by the Haveg Corporation, Newark, Del.
}

enclosed motor. A stirrer speed of $60 \mathrm{rpm}$ was found to give ample agitation. Heat was introduced by means of 11 Karbate ${ }^{12}$ bayonet heaters, $F$, supplied with steam at a gage pressure of about $30 \mathrm{lb} / \mathrm{in}^{2}$ Each heater had a surface of about 950 square inches in contact with the solution.

\footnotetext{
12 Karbate is a material consisting of carbon or graphite with binder. Carbon-base has low heat transfer; graphite-base has high heat transfer. Karbate is manufactured by National Carbon Co., New York, N. Y.
} 
See table 3 for the rate of transfer of heat through the bayonets.

The usual charge was $200 \mathrm{lb}$ of kaolin and 200 gal of acid because such a charge allowed ample excess of acid over that required to dissolve the alumina, iron oxide, and other soluble portions of the kaolin. The acid was first heated to $175^{\circ}$ to $195^{\circ} \mathrm{F}$, and then, while the steam was turned off, the entire charge of calcined kaolin was dropped into the acid through the opening, $B$, (fig. 2)

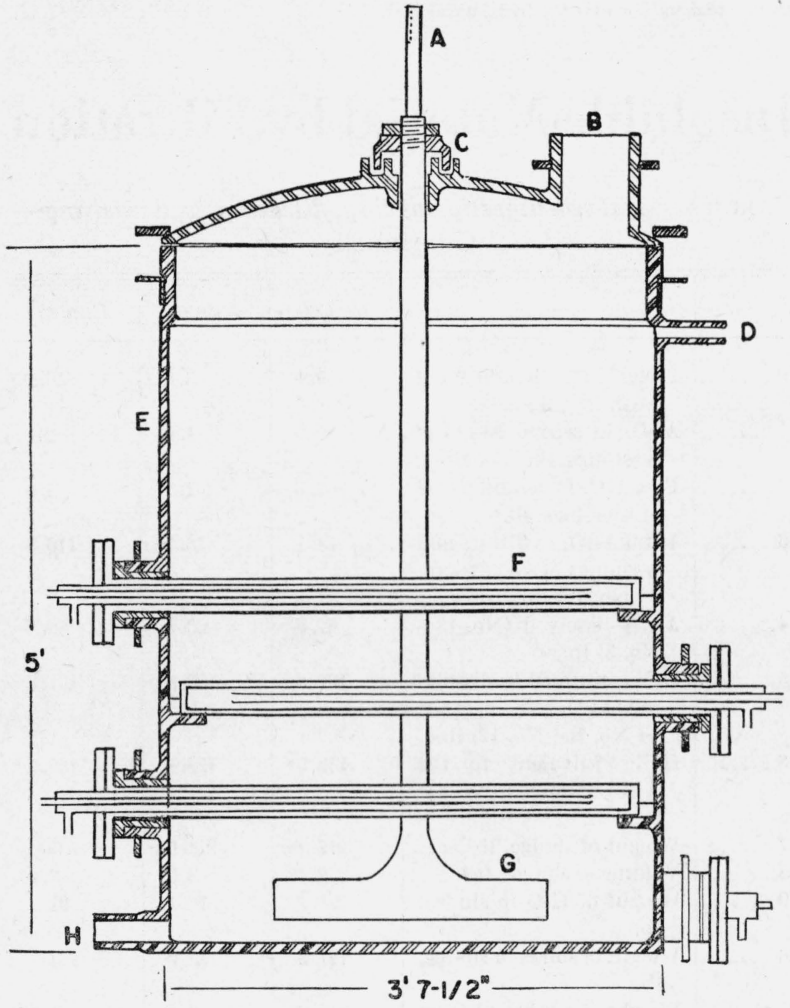

Figure 2.-Digester for decomposing clay with hydrochloric acid.

$A$, Stirrer shaft; $B$, inlet for clay; $C$, vapor seal; $D$, inlet for acid; $E$, tank made of Haveg $41 ; F$, Bayonet heater made of Karbate No. 28; $G$, pitched blade of stirrer; and $H$, outlet for digested material.

which was loosely covered after the kaolin was introduced. $C$ is a seal to prevent escape of acid, $D$ is the inlet for the acid, and $H$ is the outlet to the filter press.

The heat of reaction between the soluble constituents of the kaolin and the acid usually raised the temperature of the slurry to slightly above $212^{\circ} \mathrm{F}$ in the course of 45 minutes. This rise was more rapid with very finely divided kaolin, such as the air-floated, than with the coarser type, such as

\section{TABLE 3.-Thermal data on decomposition of kaolin}

(a) Specific heat of acid used for decomposing kaolin in run 51 was calculated from the following data:

Water equivalent of digester (Btu required to raise temperature of digester $1^{\circ} \mathrm{F}$ )

Volume of acid, gal

Specific gravity of acid at $26^{\circ} \mathrm{C}$

$\mathrm{Al}_{2} \mathrm{O}_{3}$ content, $\mathrm{lb} / \mathrm{gal}$

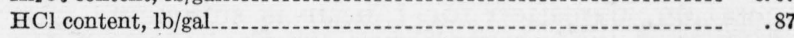

Heat added (based on weight of condensed steam) Btu ........ 68,500

Rise in temperature, ${ }^{\circ} \mathrm{F}$-............ 31.5

Time of heating, min

Rate of eooling to surroundings, ${ }^{\circ} \mathrm{F} / \mathrm{min} \ldots$

Corrected rise in temperature, ${ }^{\circ} \mathrm{F}(31.5+23 \times 0.115) \ldots \ldots \ldots \ldots \ldots$

Heat added-(rise in temperature $\times$
Specific heat, Btu/gal (for 1 deg $\mathrm{F}$ ) $=\frac{\text { water equivalent of digester) }}{\text { Corrected rise in temperature } \times}$
volume of acid

(For temperatures between $140^{*}$ and $175^{\circ} \mathrm{F}$ )

Similar data were taken for five other runs. Values for the specific heat of the acid, ranging from 7.9 to 8.5 , were obtained. The average of all the values is $8.1 \mathrm{Btu} / \mathrm{gal}$ (for $1 \mathrm{deg} . \mathrm{F}$ ).

(b) The specific heat of kaolin was determined as follows:

Two hundred pounds of calcined kaolin, cooled to a definite temperature, was dropped into $200 \mathrm{gal}$ of water at an accurately measured temperature (about $190^{\circ} \mathrm{F}$ ). From the decrease in temperature of the water, values for specific heat of kaolin were calculated. Correction for heat capacity of tanks and for dissipation of heat were made as in the determination of the specific heat of the acid for digestion of the kaolin. (See (a) above.) The average of four values is $0.23 \mathrm{Btu} / \mathrm{lb}$ for $1^{\circ} \mathrm{F}$. Although this value is useful for plant calculations, it is not to be regarded as an accurate value for the specific heat of raw or roasted kaolin.

(c) Heat of reaction of roasted kaolin with acid in run 54 was calculated from the following data:

Average temperature of calcination of roller-mill reject kaolin $\left({ }^{\circ} \mathrm{F}\right) \ldots$

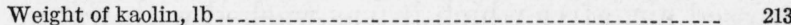

Volume of acid, sp gr 1.063 at $27^{\circ} \mathrm{C}$, gal_......................... $\quad 200$

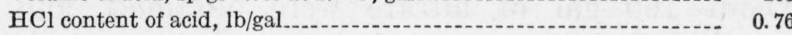

$\mathrm{Al}_{2} \mathrm{O}_{3}$ content of acid, $\mathrm{lb} / \mathrm{gal}$

Temperature of acid when kaolin was added, ${ }^{\circ} \mathrm{F}$.................. 186.8

Temperature of kaolin when added to acid, ${ }^{\circ} \mathrm{F} \ldots \ldots \ldots \ldots$

Rise in temperature during reaction, ${ }^{\circ} \mathrm{F}$

Time of reaction, min

Rate of cooling, ${ }^{\circ} \mathrm{F} / \mathrm{min}$

Corrected rise in temperature caused by reaction, ${ }^{\circ} \mathrm{F},(30.6+45 \times 0.11)_{-} \quad 35.6$

Heat added by steam to products of reaction after completion of

reaction, Btu -... 49, 900

Rise in temperature of products and digester during heating with steam after completion of reaction, ${ }^{\circ} \mathrm{F}$......................... 18

Time of heating by steam, min

Corrected rise in temperature of products, ${ }^{\circ} \mathrm{F},(21 \times 0.11+18) \ldots \ldots-20.3$

Heat capacity of products and digester, Btu/ ${ }^{\circ} \mathrm{F}, 49,900 / 20.3 \ldots \ldots . . . . .2,458$

Heat of reaction of $200 \mathrm{gal}$ of acid with $213 \mathrm{lb}$ of kaolin, Btu....... 91, 646 $35.6 \times 2458+0.2 \times 213 \times(186.8-89.6)$. (Corrected rise in temperature caused by reaction $X$ heat capacity of products and digester+specific heat $\times$ wt of kaolin $\times$ rise in temperature of kaolin).

$\mathrm{Al}_{2} \mathrm{O}_{3}$ dissolved, $\mathrm{lb} \ldots$

Heat evolved per pound of $\mathrm{Al}_{2} \mathrm{O}_{3}$ dissolved, $\mathrm{Btu}$

Similar data were taken in five other runs. The values ranged from 1,348 to $1,445 \mathrm{Btu}$. The average of all values is $1,396 \mathrm{Btu} / \mathrm{lb}$ of $\mathrm{Al}_{2} \mathrm{O}_{3}$ dissolved.

(d) The rate of transfer of heat through Karbate No. 28 bayonets averaged $0.040 \mathrm{Btu}$ in 1 minute for each square inch of surface for $1^{\circ} \mathrm{F}$ difference in temperature between steam on inside and solution on outside. The measurements were made at a steam pressure (gage) of $25 \mathrm{lb} / \mathrm{in} .{ }^{2}$, and the walls of the Karbate heaters were $7 / 16$ in. thick. The temperatures of the solutions surrounding the heaters ranged between $140^{\circ}$ and $197^{\circ} \mathrm{F}$.

(e) Total heat required for decomposition of kaolin $902 \mathrm{Btu} / \mathrm{gal}$ of acid. This is an average of five values actually obtained in the operation of the plant. Insulation of digester tanks would reduce this value somewhat. 
the roller-mill rejects. The charge was kept at a temperature of $212^{\circ}$ to $220^{\circ} \mathrm{F}$ for 2 to 3 hours by means of the Karbate heaters. Very little heat was required to maintain this temperature. Actually, very little alumina was dissolved after the first hour of digestion, and, for commercial operation, digestion for 1 hour is sufficient. An approximate determination of the heat evolved in the reaction between the kaolin and acid was made and was found to be about $1,400 \mathrm{Btu} / \mathrm{lb}$ of alumina dissolved. This value corresponds fairly closely to the theoretical ${ }^{13}$ value for the solution of $\mathrm{Al}_{2} \mathrm{O}_{3}$ in $\mathrm{HCl}$, which suggests that, after roasting, the constituents of kaolin act as if they existed as separate compounds.

Thermal data on decomposition of kaolin are given in table 3 .

13 According to the data in "Thermo-chemistry of chemical substances," by F. R. Bichowsky and F. D. Rossini (Reinhold Publishing Corporation, New York, N. Y., 1936), the heat of reaction between $\mathrm{Al}_{2} \mathrm{O}_{3}$ and $\mathrm{HCl}$ is 1,436 $\mathrm{Btu} / \mathrm{lb}$ of $\mathrm{Al}_{2} \mathrm{O}_{3}$ in 10 -percent $\mathrm{HCl}$ and $1,371 \mathrm{Btu} / \mathrm{lb}$ of $\mathrm{Al}_{3} \mathrm{O}_{3}$ in 1-percent $\mathrm{HCl}$. As the final solutions in this work were quite complex and contained hydrochloric acid in concentrations somewhere between 1 and 10 percent, exact theoretical values are not to be expected.

\section{Separation of Silica and Other Insoluble Material by Filtration}

The slurry in the digester was cooled to $130^{\circ}$ to $140^{\circ} \mathrm{F}$ by turning off the steam and circulating cooling water through the bayonet heaters. From the digester the cooled slurry was pumped into a filter press by means of a Duriron sludge pump, which maintained a pressure up to $20 \mathrm{lb} / \mathrm{in}^{2}$. The frames ( 24 by 24 by 2 in.) and plates were made of pine, and the cloths were made of Vinyon (a fabric compounded of vinyl acetate and vinyl chloride). After all the slurry was pumped into the press, the filter cake was blown dry with compressed air, after which it was washed with water. About 160 gal of filtrate were obtained, and usually a little over 100 gal of water were used for washing.

The data on the three digestions and filtrations given in table 4 illustrate the performance of the digester and filter press.

TABLE 4.-Data on digestion of clay, filtration, and washing

\begin{tabular}{|c|c|c|c|c|}
\hline & . & Run 60 & Run 61 & Run 65 \\
\hline $1 \ldots$ & Weight of calcined kaolin & 200 & 200 & 250 \\
\hline $2 \ldots$ & $\begin{array}{l}\text { used, lb. } \\
\text { Volume of hydrochloric } \\
\text { acid used, gal. }\end{array}$ & 200 & 200 & 250 \\
\hline 3. & $\mathrm{Al}_{2} \mathrm{O}_{3}$ in acid, $\mathrm{lb}$ & 15.2 & 16. 2 & 30 \\
\hline 4 & $\begin{array}{l}\text { A vailable } \mathrm{Al}_{2} \mathrm{O}_{3} \text { in kaolin, } \\
\text { lb. }\end{array}$ & 63.6 & 61.0 & 88 \\
\hline 5 & $\begin{array}{l}\text { Alumina to be expected in } \\
\text { filtrate and washings } \\
\text { (No. } 3+\text { No. 4), } 1 \mathrm{lb} \text {. }\end{array}$ & 78.8 & 77.2 & 118 \\
\hline $6 \ldots$ & $\begin{array}{l}\text { Free } \mathrm{HCl} \text { in acid used for } \\
\text { digestion, lb. }\end{array}$ & 215 & 155 & 275 \\
\hline 7 & $\begin{array}{l}\mathrm{Al}_{2} \mathrm{O}_{3} \text { in filtrate (no wash- } \\
\text { ings), lb. }\end{array}$ & 66.6 & 67.6 & 103.5 \\
\hline & $\begin{array}{l}\text { Free } \mathrm{HCl} \text { in filtrate (no } \\
\text { washings), lb. }\end{array}$ & 70.0 & 22.6 & 70.0 \\
\hline $9 \ldots$ & $\begin{array}{l}\mathrm{Al}_{2} \mathrm{O}_{3} \text { in first } 50 \text { gal of } \\
\text { washings, } \mathrm{lb} \text {. }\end{array}$ & 9.5 & 7.5 & 10.5 \\
\hline
\end{tabular}

${ }_{1}$ Numbers in parentheses refer to the numbers in the first column of this table.
TABLE 4.-Data on digestion of clay, filtration, and washingContinued

\begin{tabular}{|c|c|c|c|c|}
\hline & & Run 60 & Run 61 & Run 65 \\
\hline $10 \ldots$ & $\begin{array}{l}\text { Free } \mathrm{HCl} \text { in first } 50 \mathrm{gal} \text { of } \\
\text { washings, lb. }\end{array}$ & 9.1 & 3.6 & 10.2 \\
\hline $11 \ldots \ldots$ & $\begin{array}{l}\mathrm{Al}_{2} \mathrm{O}_{3} \text { in second } 50 \text { gal of } \\
\text { washings, lb. }\end{array}$ & 2.0 & 1.6 & 2.5 \\
\hline $12 \ldots$ & $\begin{array}{l}\text { Free } \mathrm{HCl} \text { in second } 50 \text { gal } \\
\text { of washings, lb. }\end{array}$ & 2.3 & 1.5 & 3.5 \\
\hline 13.-- & $\begin{array}{l}\text { Total } \mathrm{Al}_{2} \mathrm{O}_{3} \text { in filtrate and } \\
\text { washings (No. } 7+\text { No. } \\
9+\text { No. 11) lb. }\end{array}$ & 78.1 & 76.7 & 116.5 \\
\hline 14 & $\begin{array}{l}\mathrm{Al}_{2} \mathrm{O}_{3} \text { dissolved (No. } 13- \\
\text { No. 3) lb. }\end{array}$ & 62.9 & 60.5 & 86.5 \\
\hline 15 & $\begin{array}{c}\mathrm{HCl} \text { consumed in dissolv- } \\
\text { ing } \mathrm{Al}_{2} \mathrm{O}_{3} \text { No. } 6-(\mathrm{No} \text {. } \\
8+\mathrm{No}, 10+\text { No. 12) lb. }\end{array}$ & 133.6 & 127. 3 & 191.3 \\
\hline 16 & $\begin{array}{l}\mathrm{HCl} \text { equivalent to the } \\
\mathrm{Al}_{2} \mathrm{O}_{3} \text { dissolved (No. 14) } \\
\text { lb. }\end{array}$ & 132.9 & 129.8 & 185.6 \\
\hline 17. & Weight of sludge, lb & 217 & 210.0 & 235 \\
\hline $18 \ldots$ & Volume of sludge, $\mathrm{ft}^{3}{ }^{3}$ & 2.7 & 3.0 & 3.9 \\
\hline 19 & $\begin{array}{l}\text { Weight of } \mathrm{H}_{2} \mathrm{O} \text { in sludge, } \\
\text { lb. }\end{array}$ & 95.7 & 76.1 & 91 \\
\hline 20 & $\begin{array}{l}\text { Weight of solids in sludge, } \\
\text { lb. }\end{array}$ & 121.3 & 133.9 & 144 \\
\hline 21. & $\begin{array}{l}\text { Weight of soluble } \mathrm{Al}_{2} \mathrm{O}_{2} \text { in } \\
\text { sludge, lb. }\end{array}$ & 0.22 & 0.08 & 0.45 \\
\hline 22 & $\begin{array}{l}\text { Weight of free } \mathrm{HCl} \text { in } \\
\text { sludge, lb. }\end{array}$ & .22 & .21 & .60 \\
\hline 23. & $\begin{array}{l}\mathrm{HCl} \text { combined with } \mathrm{Al}_{2} \mathrm{O}_{3} \\
\text { in sludge, lb. }\end{array}$ & .47 & .17 & .97 \\
\hline 24 & Total loss in sludge & $\begin{array}{l}0.22 \quad \mathrm{~b} \\
\mathrm{Al}_{2} \mathrm{O}_{3}+ \\
0.69 \quad \mathrm{lb} \\
\mathrm{HCl}\end{array}$ & $\begin{array}{l}0.08 \quad \mathrm{~b} \\
\mathrm{Al}_{2} \mathrm{O}_{3}+ \\
0.38 \quad \mathrm{lb} \\
\mathrm{HCl} .\end{array}$ & $\begin{array}{c}0.451 \mathrm{~b} \\
\mathrm{Al}_{2} \mathrm{O}_{3}+ \\
1.57 \quad \mathrm{lb} \\
\mathrm{HCl}\end{array}$ \\
\hline $25 \ldots$ & $\begin{array}{l}\text { Percentage of available } \\
\mathrm{Al}_{2} \mathrm{O}_{3} \text { recovered (No. } \\
14 / \mathrm{No} .4) \times 100 \text {. }\end{array}$ & 98.9 & 99.1 & 98.3 \\
\hline
\end{tabular}

As charged into the digester, the ignited kaolin contained the available alumina indicated. Because of the difficulties previously mentioned in maintaining the roasting furnace in good operating condition at $1,300^{\circ} \mathrm{F}$ or higher, these kaolins were heated at a slightly lower temperature than that required to expel all the water of constitution, 
with the consequent failure to render all the alumina soluble. With proper roasting, the available alumina would have been about 38 percent of the weight of the calcined clay. The alumina in the acid is a result of incomplete precipitation in previous runs and the fact that this dilute acid was used to wash crystals of aluminum chloride out of various parts of the system. This is normal procedure.

Under proper operating conditions, filtration usually required 1 hour, and the washing operation required another hour. Clear filtrates were readily obtained, and filter aids did not improve the procedure sufficiently to warrant their use. The low silica content of the alumina produced is good evidence that the filtering operation was satisfactory.

During the operation of the plant, it was found that filtration and washing required progressively more and more time, until finally 3 hours were consumed. It was then discovered that the cloths were covered with a thin film of grease (probably from the packing in the sludge pump). After washing the dried cloths in mineral spirits or gasoline, the normal time schedule of 1 hour for a filtration was reestablished.

\section{Concentration of Filtrate and Washings}

The filtrate and washings were evaporated to a relatively small volume to minimize the quantity of hydrochloric acid gas required in the next step to precipitate the aluminum as the hydrated chloride, $\mathrm{AlCl}_{3} \cdot 6 \mathrm{H}_{2} \mathrm{O}$. A concentrated solution having a specific gravity of about 1.30 and containing about $1.20 \mathrm{lb}$ of $\mathrm{Al}_{2} \mathrm{O}_{3} / \mathrm{gal}$ is satisfactory.

For this concentration a Haveg still with a capacity of 250 gal was used. The still was heated by means of bayonet heaters similar to those in the digester (fig. 2). The vapor passed up through a Haveg rectifying column 10 feet high and 24 inches in inside diameter. This column was packed with 1-inch ceramic raschig rings. From the top of the column, the vapors passed into a watercooled condenser (Karbate pipes surrounded by water). The distillate was tapped from the bottom of the condenser.

Provision was made for refluxing so that water or dilute acid which first distilled could be pumped back to the top of the rectifying column. In a typical distillation, about 40 percent of the flow of the distillate (consisting of water at first) was pumped back to the top of the rectifying column as refluxing liquid. In regular practice the refluxing was discontinued as soon as the desired amount of water was removed from the system or when the concentration of acid in the distillate became too high to permit it to be discarded (see table 4). The water distillate was discarded, and the acid distillate was retained for future decomposition of clay.

If a solution containing only water and hydrochloric acid is distilled, a point will be reached where the distillate consists of constant-boiling acid, specific gravity about 1.10. Continued distillation will not change the composition of the distillate. However, if a salt such as aluminum chloride is present, the usual constant-boiling acid will never be obtained. The behavior of such solutions is illustrated in figure 3 . The curve marked $O$ represents data obtained by distilling at atmospheric pressure without reflux a solution having the following properties and composition:

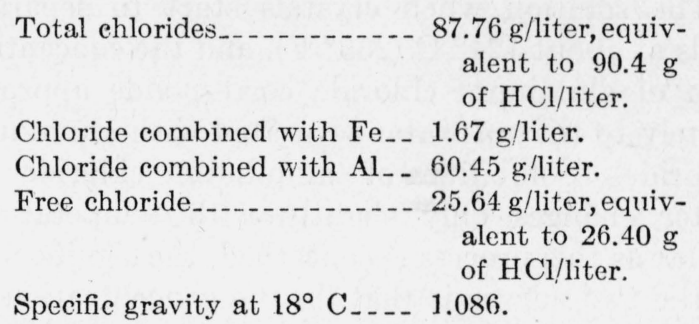

Boiling point_............ $103^{\circ} \mathrm{C}$.

This was a portion of filtrate and washings in run 48 , and is typical of all the solutions that were concentrated prior to the precipitation of the aluminum chloride with hydrochloric acid gas. The curve marked $\Delta$ represents data obtained by distilling a solution containing only water and hydrochloric acid. The hydrochloric acid content was $90.4 \mathrm{~g} /$ liter. The total chloride content of both solutions was therefore the same, and the same distilling apparatus was used for both. The point $A$ on curve $O$ where all free acid has been removed from the still happens to appear near the maximum in this particular case, but this should not be regarded as true for all solutions because 


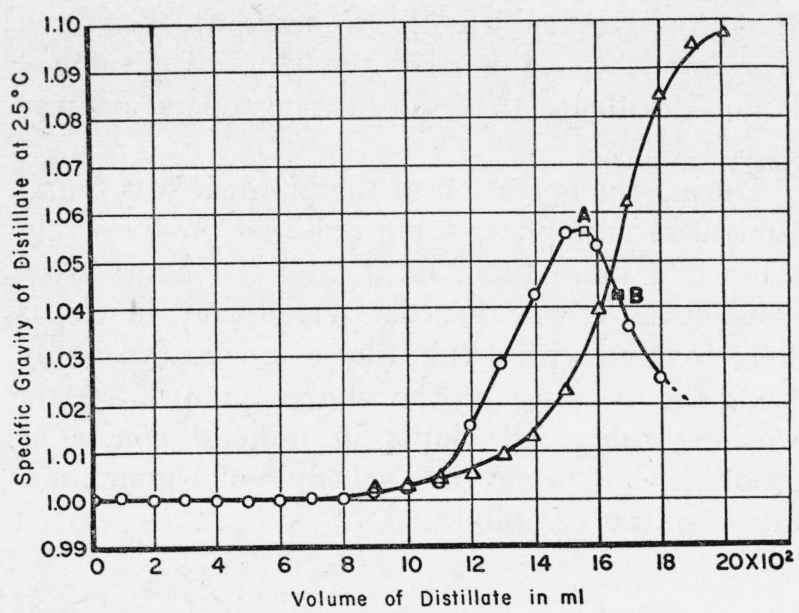

FIgure 3.-Comparison of distillates obtained from (1) a dilute hydrochloric acid solution containing aluminum chloride and (2) dilute hydrochloric acid alone.

Curve $\mathrm{O}$, dilute $\mathrm{HCl}$ containing aluminum chloride; curve $\Delta$, dilute $\mathrm{HCl}$ alone; $A$, point where all free $\mathrm{HCl}$ was distilled (temperature of still pot 117 to $120^{\circ} \mathrm{C}$ ); $B$, point where crystals of $\mathrm{AlCl}_{3} .6 \mathrm{H}_{2} \mathrm{O}$ started to separate (temperature of still pot $124^{\circ} \mathrm{C}$ ).

the position of the point at which all free acid has been distilled varies somewhat with the composition of the solution. The point $B$ at which crystals first separate in the distilling flask usually occurs shortly after all free hydrochloric acid has been distilled.

The solution when crystals start to separate boils at about $124^{\circ} \mathrm{C}\left(255^{\circ} \mathrm{F}\right)$, and the concentration of aluminum chloride corresponds approximately to that of water saturated with aluminum chloride. Solubility of aluminum chloride in water changes only slightly with temperature. As far as this process is concerned, the significance of the two curves is that, in the concentration of the filtrate and washings containing acid and aluminum chloride, hydrochloric acid of a higher specific gravity than 1.06 is never obtained as distillate. All the actual runs made during the operation of the plant yielded data in conformity with the curves of figure 3 . In the plant, concentrating the solution was always stopped soon after the maximum of the curve was passed. This maximum varies with original concentrations. Thermal data on concentration of filtrate and washings are given in table 5 .

TABLE 5.-Data on concentration of filtrate and washings

(a) Rate of distillation:

With a reflux ratio of 50 percent (that is, when 50 percent of the distillate was pumped back to the top of the still column during distillation) water was distilled at the rate of about $0.6 \mathrm{gal} / \mathrm{min}$. With no reflux, water was distilled at the rate of about $0.75 \mathrm{gal} / \mathrm{min}$. Acid was always distilled without reflux. The average rate was about $0.3 \mathrm{gal} / \mathrm{min}$.

(b) Effect of reflux on distillation:

With the reflux ratio mentioned, about 30 percent more water was obtained as distillate than with no reflux. For example, in a certain distillation $83 \mathrm{gal}$ of "water" distillate was obtained without reflux; by pumping all the distillate back into the still and then distilling as before but with a reflux ratio of 46 percent, 119 gal of water distillate was obtained. The point at which "water" distillation was regarded as complete was when the specific gravity of the distillate as it flowed from the condenser rose to 1.002.

(c) Concentration of acid in "water" distillate:

The "water" distillate, collected from the beginning of distillation up to the time when the specific gravity reached 1.002, contained $0.003 \mathrm{lb}$ of $\mathrm{HCl} / \mathrm{gal}$

(d) Composition and properties of concentrate: (material remaining in still is referred to as concentrate).

1. Free $\mathrm{HCl}$ content.-Practically no free $\mathrm{HCl}$ remains-seldom more than $0.1 \mathrm{lb} \mathrm{HCl} / \mathrm{gal}$ (see fig. 3).

2. $\mathrm{Al}_{2} \mathrm{O}_{3}$-A verage of $0.11 \mathrm{lb}$ of $\mathrm{Al}_{2} \mathrm{O}_{3} / \mathrm{lb}$ of concentrate or about $1.2 \mathrm{lb} / \mathrm{gal}$.

3. Specific gravity, 1.28 to 1.32 .

4. Volume.-Under operating conditions described, the volume of concentrate is approximately 20 percent of the original volume of filtrate and washings.

5. The weight of the concentrate is about 25 percent of the weight of filtrate and washings.

The volume of concentrate averages approximately one-fifth that of the filtrate and washings; the weight of the concentrate averages approximately one-fourth that of the filtrate and washings. These values vary rather widely. For examples, in run 60,280 gal of filtrate and washings, sp gr 1.083, weighing $2,527 \mathrm{lb}$, yielded 56 gal of concentrate, sp gr 1.311 , weighing $612 \mathrm{lb}$; and in run 63,285 gal of filtrate and washings, sp gr 1.101, weighing $2,615 \mathrm{lb}$, yielding 65 gal of concentrate, sp gr 1.312, weighing $711 \mathrm{lb}$.

(e) Total heat required to produce concentrate from filtrate and washings,

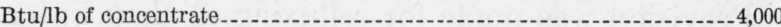

(f) Heat required to bring filtrate and washings to distilling temperature (uncorrected for heat losses of still to surroundings) Btu/gal for each ${ }^{\circ} \mathrm{F}, 10.9$.

(g) Velocity of vapor in still column, $\mathrm{ft}^{3} / \mathrm{min}$ for each square foot of cross section of column

\section{Precipitation of Aluminum Chloride, $\mathrm{AlCl}_{3} \cdot 6 \mathrm{H}_{2} \mathrm{O}$}

After concentrating the filtrate and washings in the manner described in the previous section, the cooled concentrated solution was pumped into the tank $G$, of the precipitator (fig. 4), which had a capacity of 125 gal.

By means of a glass pump located below the level of outlet $H$, the solution was circulated by pumping it to the top of the unpacked tower $D$ (9 ft. by 18 in.) mounted above tank $G$, as illustrated in figure 4. The solution thus fell against the stream of hydrochloric acid gas which entered at $E$ at the bottom of tower $D$. Any unabsorbed gas passed out at $C$ and was recirculated. The perforated plate $B$ at the top of the tower was 


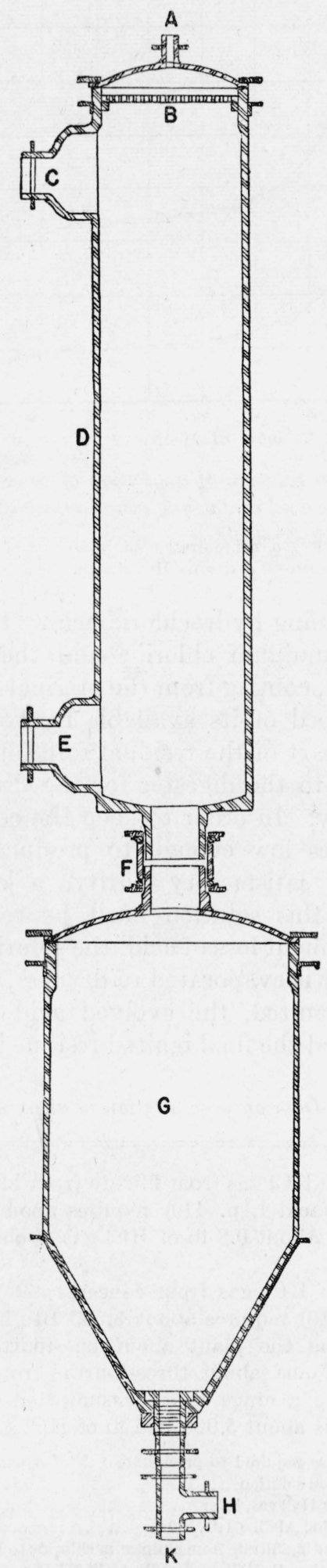

FIgURE 4.-Precipitator for aluminum chloride. inserted to break the stream of liquid to expose more surface to the opposing flow of gas. A rapid stream of liquid is desirable because better absorption is obtained, and there is less trouble from clogging of gas inlets and outlets by deposition of crystals of aluminum chloride. A desirable rate of circulation of solution through this tower is about $30 \mathrm{gal} / \mathrm{min}$. Satisfactory results were obtained in this unit by continuous operation at full capacity, but clogging of inlets and outlets by crystals of aluminum chloride often resulted if the unit remained out of operation for any extended period.

The hydrochloric acid gas was generated in still $B$ (fig. 8) from solutions containing hydrogen chloride in a sufficiently high concentration to yield the gas on boiling. The three sources of such concentrated acid were (I) filtrate from crystals of aluminum chloride obtained in a previous precipitation, (II) acid of sp gr 1.18 to 1.20 formed by cooling the gases issuing from the Herreshoff furnace during the ignition of aluminum chloride and absorbing the hydrochloric acid gas in cool constant-boiling hydrochloric acid, (III) Carboy acid, specific gravity about 1.17, supplied to make up for losses incurred in operating the plant.

Hydrochloric acid gas is absorbed more rapidly at low than at high temperatures. Because of the heat developed by dissolving the hydrochloric acid gas, it is necessary to cool the solution. ${ }^{14}$ This is most conveniently done by interposing a cooling system between the circulating pump and the top of the absorption tower. Two types of cooler were used. One was made of Karbate No. 28 pipe; the other was made of Pyrex heat exchanger pipe. Both were constructed with sweep return bends and immersed in running water. With the cooler made of 30 feet of 1-inch glass cooling pipe, the flow of liquid was so valved that about onethird of it passed through the cooler and two-thirds in a straight line from pump to top of tower. With city water at a temperature of $60^{\circ}$ to $70^{\circ} \mathrm{F}$, a satisfactory temperature was maintained in the solution in precipitator tank $G$, figure 4. Dimensions and operation of the cooling unit are necessarily quite flexible because of variations in temperature and rate of flow of hydrochloric acid gas

14 The heat to be dissipated was actually found to be about $500 \mathrm{Btu} / \mathrm{lb}$ of $\mathrm{HCl}$ absorbed. This determination was made by measuring the quantity of water passing through the cooler and its rise in temperature. 
as well as temperature and rate of flow of cooling water. For effective absorption, the temperature of the solution in tank $G$ must be maintained below $80^{\circ} \mathrm{F}$, preferably below $70^{\circ} \mathrm{F}$. Cooling capacity should be calculated on the basis of dissipation of at least $500 \mathrm{Btu} / \mathrm{lb}$ of hydrogen chloride absorbed.

During a part of the operation of the plant, two absorption units were used so that the unabsorbed hydrochloric acid gas from the unit nearing complete saturation could be absorbed in the second unit containing fresh solution.

At the beginning of the saturation with hydrochloric acid gas the concentrated solution in the precipitator has a specific gravity of 1.30 to 1.32 and contains about $1.20 \mathrm{lb}$ of $\mathrm{Al}_{2} \mathrm{O}_{3} /$ gal. The specific gravity of the solution drops as the aluminum chloride is precipitated. Usually the precipitation is discontinued when the aluminum content drops to $0.1 \mathrm{lb}$ of $\mathrm{Al}_{2} \mathrm{O}_{3} /$ gal. This corresponds to a specific gravity of 1.18 to 1.20 in the supernatant liquid. The drop in specific gravity of the solution corresponding to the drop in its alumina content is illustrated in figure 5 . It is obvious that the progress of the precipitation is indicated approximately by the specific gravity of the solution, but actual determinations of alumina were made before final disposal of the solution.

Distilling the available hydrochloric acid gas out of the carboy acid (acid III) or out of the strong acid produced in the plant (acid II) finally results in the production of constant-boiling acid that is used in a subsequent decomposition of clay. Distillation of the filtrate from the crystals of aluminum chloride (acid I) yields a solution in the stillpot containing less free acid than the conventional

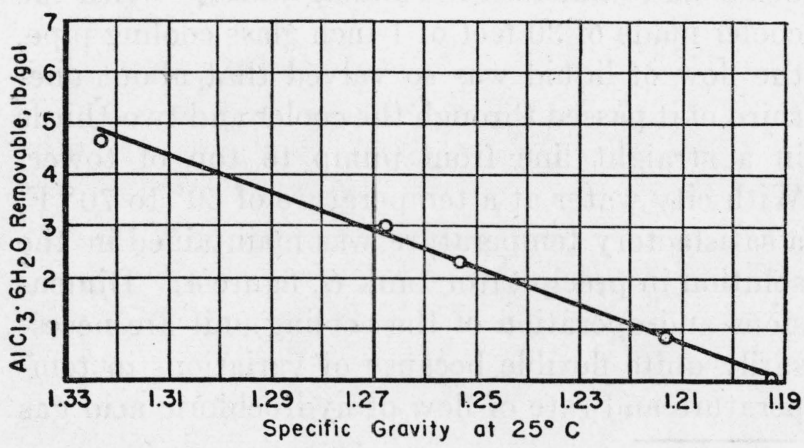

Figure 5.-Change in specific gravity with change in content of $\mathrm{AlCl}_{3} .6 \mathrm{H}_{2} \mathrm{O}$ in a solution saturated with $\mathrm{HCl}$.

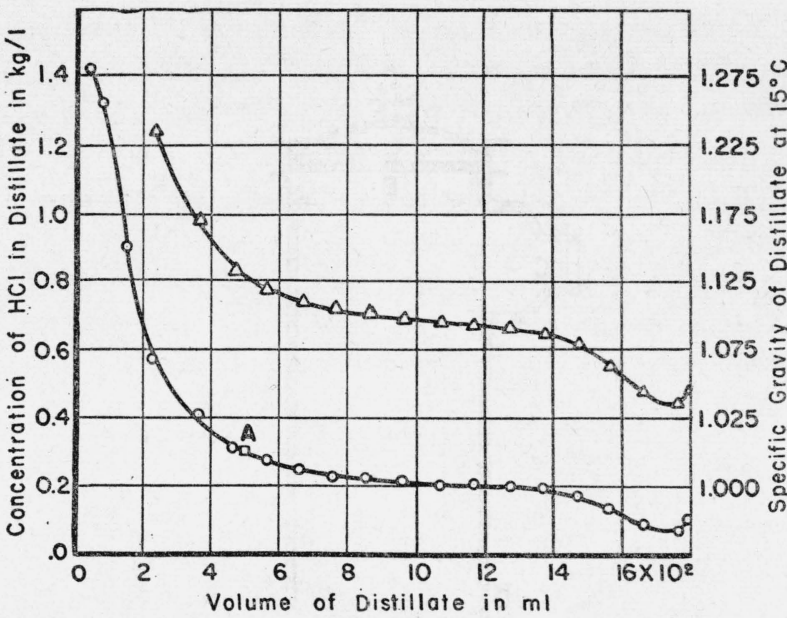

FIgURe 6.-Distillation of a solution of concentrated hydrochloric acid containing aluminum and iron.

$\Delta$, specific gravity; $o$, concentration of hydrochloric acid in distillate; $A$, point where 50 percent of the free $\mathrm{HCl}$ was distilled.

constant-boiling hydrochloric acid. This solution contains aluminum chloride and the impurities, such as iron, coming from the original clay. After being stripped of its available hydrochloric acid gas, all or part of the residual solution in the still is returned to the digester for the decomposition of more clay. In order to keep the concentration of impurities low enough to produce aluminum chloride of satisfactory purity, a certain percentage of this solution must be removed. To avoid permanent loss of acid, the solution removed at this point is evaporated to dryness, the chloride residue is ignited, the evolved acid is absorbed for reuse, and the final ignited residue is discarded.

TABLE 6.-Data on precipitation of aluminum chloride

To produce $\mathrm{HCl}$ gas from filtrate from aluminum chloride crystals (acid I, p. 419) requires about $9,000 \mathrm{Btu} / \mathrm{lb}$ of $\mathrm{HCl}$ gas. About $0.8 \mathrm{lb}$ of $\mathrm{HCl}$ gas is obtained from 1 gal of fillrate.

To produce $\mathrm{HCl}$ gas from concentrated acid (acid II and III, p. 419) requires about $3,500 \mathrm{Btu} / \mathrm{lb}$ of $\mathrm{HCl}$ gas.

In operating the plant about one-fourth of the gas comes from I and about three-fourths from II and III. Therefore, the average heat consumption in generating gaseous $\mathrm{HCl}$ is about $5,000 \mathrm{Btu} / \mathrm{lb}$ of $\mathrm{HCl}$ gas required.

Pounds of $\mathrm{HCl}$ gas required to precipitate $1 \mathrm{lb}$ of $\mathrm{AlCl}_{3} \cdot 6 \mathrm{H}_{2} \mathrm{O}$

from concentrated solution.... 0.5 to 0.7

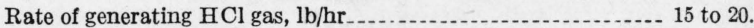

Rate of precipitating $\mathrm{AlCl}_{3} \cdot 6 \mathrm{H}_{2} \mathrm{O}, \mathrm{lb} / \mathrm{hr} \ldots \ldots . .$.

Loss of $\mathrm{HCl}$ by heating filtrate from aluminum chloride to obtain gas for precipitation, $\mathrm{lb} \mathrm{HCl}$ gas lost/lb $\mathrm{AlCl}_{3} .6 \mathrm{H}_{2} \mathrm{O}$ produced in this step. 0.188 . 
The amount of solution to be removed to keep the product satisfactory depends on the original soluble impurities in the clay. By far the most important of these is iron.

Figure 6 represents data obtained in the distillation at atmospheric pressure of a typical filtrate from aluminum chloride crystals (I, p. 419). At the beginning of the distillation the solution had the following composition:

\footnotetext{
$\mathrm{Al}_{2} \mathrm{O}_{3}=28.4 \mathrm{~g} /$ liter, equivalent to $60.9 \mathrm{~g}$ of $\mathrm{HCl} /$ liter. $\mathrm{Fe}_{2} \mathrm{O}_{3}=6.8 \mathrm{~g} /$ liter, equivalent to $9.3 \mathrm{~g}$ of $\mathrm{HCl} /$ liter.

Total $\mathrm{Cl}=347.6 \mathrm{~g} /$ liter, equivalent to $351.4 \mathrm{~g}$ of $\mathrm{HCl} /$ liter.
}

Free $\mathrm{HCl}=287.2 \mathrm{~g} /$ liter, equivalent to $2.39 \mathrm{lb}$ of $\mathrm{HCl}$ /gal.

To obtain these data the usual type of distilling flask was used, and 2 liters of solution were placed in the flask at the start. It is noteworthy that much of the distillate contained less acid than the conventional constant-boiling hydrochloric acid (compare with fig. 3). The slight upturn of the curve at the end of the distillation is caused by decomposition of aluminum chloride as the mass goes to dryness.

Data on precipitation of aluminum chloride are given in table 6 .

\section{Filtration of Aluminum Chloride}

From the bottom of the conical tank, figure 4, a 2-inch pipe line led directly to a 20 -inch rubbercoated centrifuge with a perforated basket. ${ }^{15} \mathrm{~A}$ valve at the bottom of the tank controlled the flow of the slurry of liquid and crystals to the centrifuge. An asbestos filter cloth was used to retain the crystals in the basket, which holds about $80 \mathrm{lb}$ of aluminum chloride. A slurry containing about $3 \mathrm{lb}$ of aluminum chloride crystals, $\mathrm{AlCl}_{3} \cdot 6 \mathrm{H}_{2} \mathrm{O}$, per gallon filtered quite satisfactorily. In fact, a thick slurry, provided that it flowed freely, gave better performance in the centrifuge than one containing only a few crystals. With a thick slurry, $80 \mathrm{lb}$ of the chloride

15 The centrifuge was purchased from Fletcher Works, Philadelphia, Pa. can easily be obtained in $15 \mathrm{~min}$ of centrifuging.

After the basket was full, the crystals were washed with a spray of hydrochloric acid, specific gravity between 1.13 and 1.20 . One gallon of acid was sufficient for an 80-lb basket of aluminum chloride, and the washing was completed in less than a minute, with the basket spinning at full speed. The purity of the final product depends largely upon the washing. ${ }^{16}$ If alumina of a specially high purity is desired, the amount of washing may be doubled or trebled.

16 Microscopical examination of the crystals by Charles Proffer Saylor at the National Bureau of Standards indicates that ferric chloride, which is the chief impurity in the mother liquor, adheres to the surface of the crystal and is not a part of it, even if the solution from which the aluminum chloride is precipitated contains as much as $0.10 \mathrm{lb}$ of ferric oxide, $\mathrm{Fe}_{2} \mathrm{O}_{3}$, per gal.

\section{Conversion of Aluminum Chloride to Aluminum Oxide and Recovery of the Resulting Acid}

In preliminary laboratory experiments it was shown that aluminum chloride, $\mathrm{AlCl}_{3} \cdot 6 \mathrm{H}_{2} \mathrm{O}$, can be converted to the oxide by ignition in a muffle furnace or over a free flame at $1,000^{\circ} \mathrm{C}\left(1,832^{\circ} \mathrm{F}\right)$. A gas-fired muffle furnace, having a capacity of 36 cubic feet was installed and used during the first period of operation of the plant, but it was soon realized that ignition of larger quantities of aluminum chloride packed in saggers in a muffle furnace required an excessively long time for satisfactory elimination of chloride and for heating and cooling the furnace. Further laboratory experiments indicated that, if the aluminum chloride could be constantly agitated during ignition, chloride could be eliminated satisfactorily at a lower temperature than that which was necessary in the original muffle furnace. Consequently, the muffle-fired Herreshoff furnace shown in figure 7 was purchased from Nichols Engineering \& Research Corporation, New York, N. Y. to replace the original muffle furnace.

In the Herreshoff furnace, the aluminum chloride was constantly agitated by the rabble arms as it passed downward over the heated 

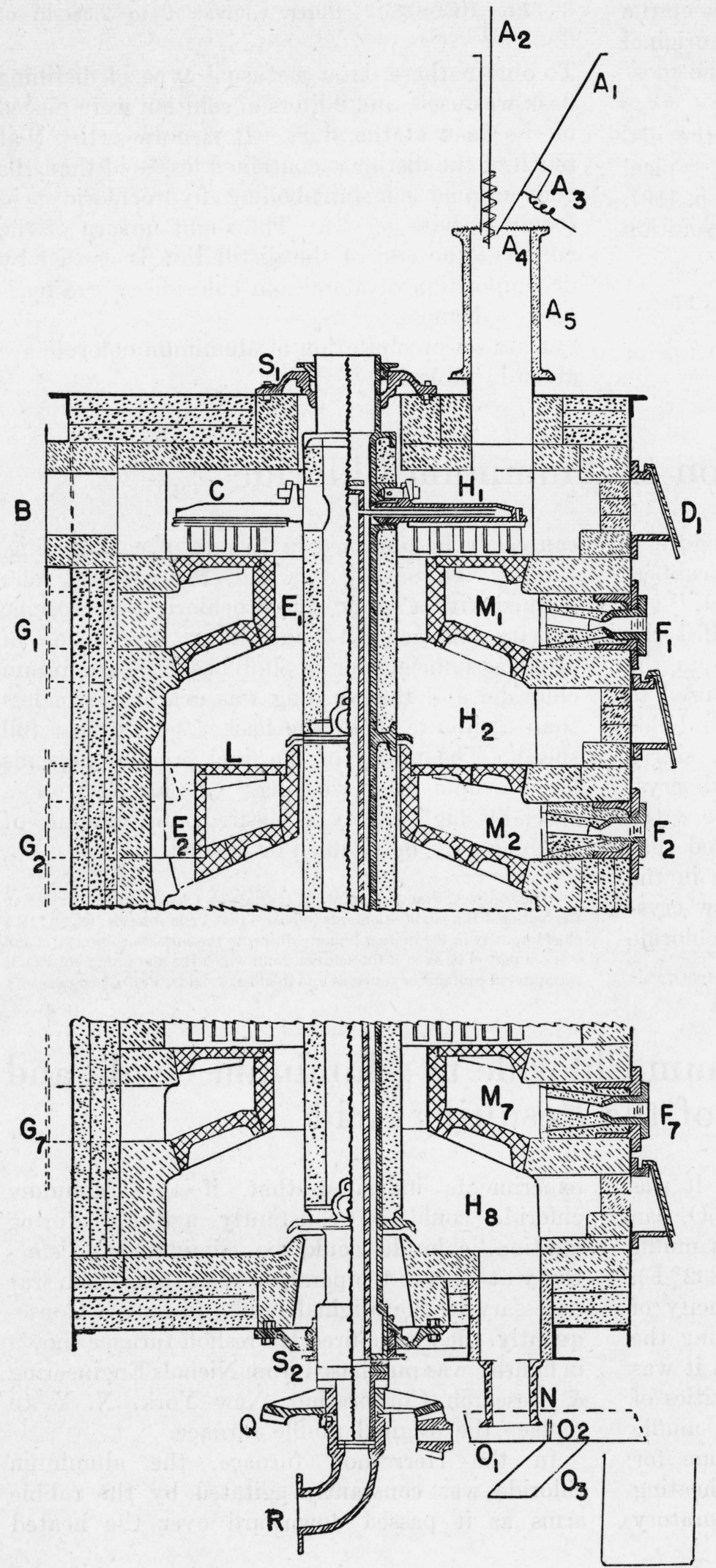

Figure 7.-Muffle-fired Herreshoff furnace.

$A=$ feeding hopper for the aluminum chloride. $\mathrm{A}_{2}=\mathrm{a}$ conveyor screw.

$A_{3}=a$ Syntron vibrator.

$\mathrm{A}_{4}=$ an asbestos cloth to prevent escape of gas.

$A_{5}=a$ tile pipe.

$\mathrm{B}=$ the outlet for the vapors of $\mathrm{HCl}$ and water formed by heating $\mathrm{AlCl}_{3} \cdot 6 \mathrm{H}_{2} \mathrm{O}$.

$\mathrm{C}=\mathrm{a}$ high-silicon rabble arm.

$D_{1}=$ an observation port.

$E_{1}$ and $E_{2}=$ passages to next lower hearths.

$F_{1}, F_{2}$, and $F_{7}=$ gas burners.

$\mathrm{G}_{1}, \mathrm{G}_{2}$, and $\mathrm{G}_{7}=$ outlets to flue for products of combustion of gas.

$\mathrm{H}_{1}, \mathrm{H}_{2}$, and $\mathrm{H}_{8}=$ hearths.

$\mathrm{L}=$ "Carbofrax" heat-conducting refractory.

$\mathbf{M}_{1}, \mathbf{M}_{2}$, and $\mathbf{M}_{7}=$ muffles.

$\mathrm{N}=$ Pyrex glass pipe.

$\mathrm{O}_{1}=$ delivery chute.

$\mathrm{O}_{2}=\mathrm{a}$ dam to keep alumina at proper level to seal the outlet.

$\mathrm{O}_{3}=\mathrm{a}$ Syntron vibrator.

$\mathrm{Q}=$ driving gear.

$\mathrm{R}=$ inlet for air to cool shaft and rabble arms. $\mathrm{S}_{1}$ and $\mathrm{S}_{2}=$ seals.

Inside diameter of hearths, 36 in. Effective area of a single hearth, about 825 in. $^{2}$ 
hearths. The chloride and resulting oxide were never in contact with the products of combustion of the fuel gas.

The muffles of the Herreshoff furnace were made of Carbofrax, the center shaft was made of cast iron covered with acid-proof cement, and most of the exposed metal parts were made of high-silicon iron or other acid-resisting metal. The center shaft and hollow rabble arms were cooled by a forced air current in the conventional way. Attack by the hydrochloric acid gas was not excesssive but was greatest in the upper and cooler portion of the furnace where water and acid condensed. During the operation of both the original muffle and Hereshoff furnaces, the inside of the furnace was maintained at slightly less than atmospheric pressure by the rubbercoated exhaust fan shown in the flow sheet, figure 8 , which pulled the water vapor and the hydrochloric acid gas from the top of the furnace through cooler $B$, figure 8 , and forced the moist hydrochloric acid gas into the bottom of the absorption tower. After leaving the absorption tower, the gases were forced through the waste tower.

The first and hottest portion of the 4-inch pipe line from the top of the Herreshoff furnace to the cooler was made of Carbofrax pipe; the remainder was made of 4-inch Haveg pipe. As operated, the maximum concentration by volume of hydrochloric acid gas in the 4-inch pipe line between the furnace and the cooler was 12 percent; between the cooler and absorption tower it was 8.0 percent; between the absorption tower and waste tower it was less than 1 percent; and at the exit of the waste tower practically no hydrochloric acid remained. The low concentration of hydrochloric acid gas in the line between the furnace and the cooler indicates that much air was drawn into the system.

Better performance could be obtained with respect to the ratio of hydrochloric acid gas to the other gases in this line if the rate of feed of chloride could be increased, but the absorption system was not adequate for an increased rate of feed. ${ }^{17}$ Feeding the aluminum chloride into the top of the furnace presented somewhat of a problem because

\footnotetext{
17 The Herreshoff furnace was larger than necessary for the capacity of the rest of the plant. It was purchased as a rebuilt furnace after the other parts of the plant were in operation. At the time of purchase there was no choice as to size and only a limited choice as to design.
}

of the tendency of the crystals to stick together. This stickiness increased in a humid atmosphere. It was found that the chloride could be readily handled if $1 \mathrm{lb}$ of aluminum oxide was mixed with $10 \mathrm{lb}$ of chloride. The final satisfactory equipment for feeding this mixture of chloride and oxide consisted of a hopper equipped with a Syntron vibrator, mounted over the inlet to the furnace. Inside of the hopper was a large vertical motordriven screw such as is used in screw conveyors. This screw extended into the opening of the furnace. Its speed of rotation determined the rate of feeding of the chloride. When the hopper was kept partly or entirely filled, air did not enter the furnace at the inlet, nor did hydrochloric acid gas escape.

During calcination, finely powdered alumina has a tendency to collect in the gas outlet of the furnace. Provision must therefore be made to remove this dust about once a week to prevent retardation of the gases on their way to the absorbers.

The oxide emerging from the bottom of the furnace was removed by a Syntron vibrating conveyor that was so arranged and regulated that the lower end of the 6 -inch glass outlet pipe was always filled with oxide. This prevented air from entering the furnace and diluting the hydrochloric acid gas issuing from the top.

The Herreshoff furnace in which the aluminum chloride was constantly agitated during ignition was far more satisfactory than the ordinary muffle furnace because it made the conversion of chloride

TABLE 7.-Data on conversion of aluminum chloride to aluminum oxide and recovery of the resulting hydrochloric acid

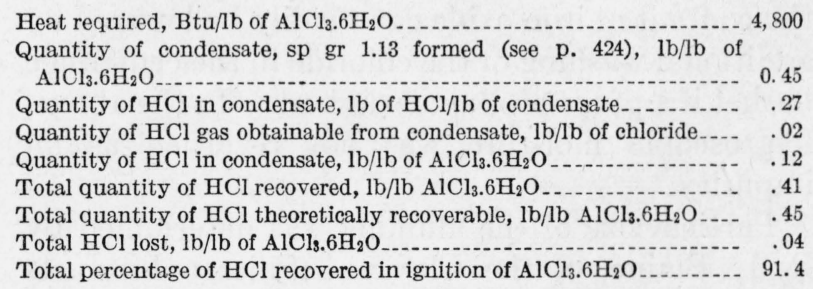

Hydrochloric acid gas balance.-A certain amount of hydrochloric acid gas is necessary to maintain the process. Practically all acid lost in the plant escapes as the gas during the precipitation and ignition of aluminum chloride: Carboy acid, sp gr 1.17, was used to make up for losses during operation. By distilling the available hydrochloric acid gas from the makeup acid, a satisfactory gas balance was maintained. Less carboy acid will be required as recovery of the gas from the ignition of chloride is improved. In a large installation the makeup acid could probably be best supplied from salt and sulfuric acid. 
to oxide a continuous process and effected elimination of chloride at a lower temperature. The oxide obtained at a minimum of $750^{\circ} \mathrm{C}\left(1,382^{\circ} \mathrm{F}\right)$ in the Herreshoff furnace contained about the same amount of chloride ( 0.10 to 0.25 percent) as remained in the oxide obtained in the muffle furnace at $950^{\circ} \mathrm{C}\left(1,742^{\circ} \mathrm{F}\right)$ without agitation during ignition.

The ignition of the chloride proceeds according to the equation

$$
2 \mathrm{AlCl}_{3} \cdot 6 \mathrm{H}_{2} \mathrm{O}+\text { heat }=\mathrm{Al}_{2} \mathrm{O}_{3}+6 \mathrm{HCl}+9 \mathrm{H}_{2} \mathrm{O} .
$$

It is evident that when the gases resulting from this ignition are drawn through the cooler, a certain amount of aqueous hydrochloric acid condenses. This condensate had a specific gravity of about 1.13 , and was drained into the Karbate still for later generation of hydrochloric acid gas and decomposition of more clay. The major portion of the hydrochloric acid gas passed through the cooler and was absorbed in cool hydrochloric acid of constant-boiling strength in an absorption tower by the same technic as was used for the precipitation of aluminum chloride (see fig. 4 and description under precipitation of aluminum chloride). In this way the constant-boiling acid was built up to acid of sp gr 1.18 to 1.20 (acid II, p. 419), which was then pumped into the Karbate still and heated to produce hydrochloric acid gas for precipitation of aluminum chloride.

Data on conversion of aluminum chloride to oxide are given in table 7 .

\section{Properties of the Alumina Produced}

The alumina at first obtained in the pilot plant had an average purity of about 99.6 percent. The significant impurities were 0.25 percent of chlorine, 0.04 percent of iron oxide, and 0.06 percent of silica. Spectrochemical tests indicated that the only other impurities were traces of barium, calcium, copper, lithium, magnesium, manganese, and lead. A trace here represents less than 0.01 percent. In more recent calcinations of the aluminum chloride, the resulting alumina had a purity of about 99.8 percent, and contained only 0.1 percent of chlorine, probably because of better operation and better control of the Herreshoff furnace with respect to temperature of hearths and constant rate of feeding. The chloride content can be further reduced by longer heating at higher temperatures. As has already been stated, the content of iron oxide can readily be lowered by additional washing of the chloride in the centrifuge basket if a purer product is desired. In the above, hygroscopic moisture was not regarded as an impurity.

Particle size of the alumina was determined by R. L. Blaine, of the Clay and Silicate Products Division at the National Bureau of Standards. The method of absorption of nitrogen at the temperature of liquid nitrogen described by $\mathrm{P}$. H. Emmet ${ }^{18}$ was used, and the values were con-

\footnotetext{
${ }^{18} \mathrm{~A}$ new method for measuring surface areas of finely divide $\mathrm{d}$ materials and for determining the size of particles. Symposium on new methods for particle size determination in the sub-sieve range. A. S. T. M. 1941 , p. 95 to 105 .
}

firmed by H. F. McMurdie by measurements with an electron microscope. The particles of alumina produced in the Herreshoff furnace had diameters between 0.02 and 0.04 micron. That produced by calcination of aluminum chloride in the original muffle furnace, that is, without rabbling during the ignition, had diameters of about 0.1 micron. This extreme fineness is said to be a disadvantage in the electrolytic reduction of alumina to the metal because of dusting.

The Physical Chemistry Section of the National Bureau of Standards had no particular difficulty from dusting or frothing in an experimental electrolysis in which a slug of $118 \mathrm{~g}$ of aluminum metal was produced. A pure graphite crucible served as the cathode, and a pure graphite rod was used as the anode. The electroly te was molten cryolite. The metal contained 99.5 percent of aluminum, 0.28 percent of iron, and 0.22 percent of silicon. In considering the impurities in this metal, it should be noted that silicon and iron accumulate in the first metal that is reduced, and that purer metal could be obtained on continued electrolysis. The alumina contained 0.03 percent of iron and 0.06 percent of silicon. The cryolite contained about the same percentage of impurities as the alumina.

X-ray examination by H. C. Vacher of the Metallurgical Division of the Bureau showed that the alumina produced by ignition in the Herreshoff furnace at a maximum temperature 
of $750^{\circ} \mathrm{C}$ was $\gamma$-alumina; that produced in the muffle by ignition at a temperature of $950^{\circ}$ to $1,000^{\circ} \mathrm{C}$ was $\alpha$-alumina. The $\gamma$-alumina produced in the Herreshoff furnace at $750^{\circ} \mathrm{C}$ can be converted to $\alpha$-alumina by heating for 1 hour or more, at or above $1,150^{\circ} \mathrm{C}$. The X-ray pattern produced by $\gamma$-alumina which had been heated for 5 hours at $1,000^{\circ} \mathrm{C}$ indicated a partial conversion to the $\alpha$-form. The results of the X-ray examinations are in approximate agreement with those obtained by M. H. Jellinek and I. Fankuchen ${ }^{19}$

The alumina produced by this process is superior to any alumina on the market at present for polishing certain metallographic specimens. A study of this is being made by G. A. Ellinger.

In the preparation of enamels to be used at high

${ }^{10}$ Ind. Eng. Chem. 37, 158, (1945). temperatures, W. N. Harrison of the Clay and Silicate Products Division of the Bureau obtained exceptionally satisfactory results with the alumina produced in this pilot plant. The favorable results can probably be attributed to its extreme fineness, rather than to the purity of the alumina.

The alumina produced in the Herreshoff furnace is appreciably hygroscopic. For example, on exposure to the atmosphere it readily absorbs 3 to 4 percent of moisture. If a portion is covered with water and then dried at $110^{\circ} \mathrm{C}$, it will retain moisture up to 8 to 10 percent of its original weight. This moisture can again be driven off at $750^{\circ}$ C. The resulting ignited oxide will again absorb moisture just as it did originally. This hygroscopicity can be eliminated by ignition at a higher temperature. Such ignition may be necessary if the alumina is to be reduced to metal in the Hall process.

\section{Cost of the Alumina Produced}

The cost of construction of a commercial plant for the extraction of alumina from clay is impossible to estimate on the basis of a small pilot plant because the materials of construction used in the two differ very greatly. However, operation of the pilot plant yielded data from which costs of raw materials, heat input, and acid losses can be estimated.

The cost estimates on heat input in table 8 were made on the basis of actual pilot-plant data that were obtained by burning city gas. The gas furnished $600 \mathrm{Btu} / \mathrm{ft}^{3}$, and $2.7 \mathrm{ft}^{3}$ were assumed to produce $1 \mathrm{lb}$ of steam at 25 -lb gage pressure. One pound of this steam released $933 \mathrm{Btu}$ upon condensing. The cost of the city gas was $\$ 0.90$ per $1,000 \mathrm{ft}^{3}$. In converting to the basis of coal, it was assumed that the cost of coal was $\$ 6.00$ a ton, and that $1 \mathrm{lb}$ of coal produced $8 \mathrm{lb}$ of steam. It was further assumed that coal could be burned as efficiently as gas. This last assumption may be rather optimistic, but it is safe to say that in well-insulated furnaces and boilers the efficiency of burning coal is equal to or greater than was actually obtained with gas in the present pilot plant. The steam boiler was insulated, but all the calcining furnaces, stills, and digester were without insulation. On an average, $620 \mathrm{lb}$ of alumina were obtained from 1 ton of kaolin.
TABLE 8.-Cost estimates on producing alumina

(a) HEAT INPUT PER TON OF ALUMINA

\begin{tabular}{|c|c|c|c|}
\hline \multirow{2}{*}{ Steps in process } & \multirow{2}{*}{ Btu required } & \multicolumn{2}{|c|}{ Cost } \\
\hline & & Gas & Coal \\
\hline Roasting of kaolin.-. & $10,900,000$ & $\$ 16.35$ & $\$ 2.51$ \\
\hline Digestion of kaolin. - & $5,820,000$ & 15.13 & 2. 34 \\
\hline Concentration of filtrate and washings_- & $82,600,000$ & 214.76 & 33. 20 \\
\hline $\begin{array}{l}\text { Formation of } \mathrm{HCl} \text { gas for precipitation of } \\
\mathrm{AlCl}_{3} 6 \mathrm{H}_{2} \mathrm{O}\end{array}$ & $4,980,000$ & 12. 94 & 2. 00 \\
\hline Conversion of $\mathrm{AlCl}_{3} .6 \mathrm{H}_{2} 0$ to $\mathrm{Al}_{2} \mathrm{O}_{3}$ & $45,500,000$ & 68.25 & 10.46 \\
\hline Total_- & $149,900,000$ & 327.43 & 50.51 \\
\hline
\end{tabular}

(b) ACID LOSSES

In the calcination of $\mathrm{AlCl}_{3} .6 \mathrm{H}_{2} \mathrm{O}, 8.6$ percent of the evolved $\mathrm{HCl}$ was lost. This was replaced by carboy acid, which cost $\$ 0.0235$ per $\mathrm{lb}$ at the plant. Cost of acid lost in calcining $\mathrm{AlCl}_{3} .6 \mathrm{H}_{2} \mathrm{O}$ therefore is ...... $\$ 22.77 /$ ton of

Acid lost in producing hydrochloric acid gas by boiling

filtrate from aluminum chloride crystals _.......... $0.188 \mathrm{lb}$ of $\mathrm{HCl} / \mathrm{lb}$ of $\mathrm{AlCl}_{3} .6 \mathrm{H}_{2} \mathrm{O}$ produced in this step.

As only about one-fourth of the gaseous $\mathrm{HCl}$ comes from this source, the loss of $\mathrm{HCl}$ per ton of $\mathrm{Al}_{2} \mathrm{O}_{3}(500 \mathrm{lb} \times$ $4.74 \times 0.188)=445 \mathrm{lb}$

Carboy acid equivalent of $445 \mathrm{lb}$ of $\mathrm{HCl}$ gas............... 1,270 lb.

Cost of carboy acid at $\$ 0.0235 / \mathrm{lb} \ldots \ldots \ldots \ldots$ $\mathrm{Al}_{2} \mathrm{O}_{3}$.

Total cost of makeup acid $\mathrm{Al}_{2} \mathrm{O}_{3}$.

(c) KAOLIN $\$ 5.00 /$ tonof $\mathrm{Al}_{2} \mathrm{O}_{3}$.

(d) WATER

Cost of cooling water.................... $\$ 1$ tonof $\mathrm{Al}_{2} \mathrm{O}_{3}$.

Total cost of producing 1 ton of alumina (exclusive of plant and personnel)
$\$ 109.13$. 
It is evident from the foregoing cost estimates that improvement must be mainly sought in three items, namely, (1) heat required for concentration of filtrate and washings, (2) heat required for conversion of aluminum chloride to the oxide, and (3) acid losses.

With efficient heat exchangers and the utilization of waste heat from furnace gases, the cost of evaporating the filtrate and washings can probably be reduced 75 percent. With insulation of the Herreshoff furnace, the cost of converting aluminum chloride to the oxide can undoubtedly be halved. As the largest item in the tabulation of costs is acid losses, most attention should be given to this. At the time the plant was built, tall absorption towers and acid-proof gas fans were difficult to obtain. Consequently, a certain amount of makeshift equipment was used, which resulted in the losses of acid shown. However, in the manufacture of hydrochloric acid nearly 100 percent of the acid is recovered under similar circumstances. This indicates that the cost of acid losses need not exceed $\$ 10.00$ per ton of alumina.

With the suggested changes, it is not unreasonable to expect the cost of producing a ton of alumina in the pilot plant to be in the neighborhood of $\$ 60.00$ a ton on the basis of coal as fuel.

\section{Special Equipment}

One of the major problems in constructing a plant in which hydrochloric acid and its salts are to be handled is the procurement and selection of suitable materials of construction. In the descriptive text, mention has been made of tanks, towers, and stills made of Haveg and Karbate for hydrochloric acid solutions at various concentrations and temperatures; of furnaces built of ordinary refractories and with Carbofrax muffles; of ceramic and Carbofrax ducts for hydrochloric acid gas at elevated temperatures; of rubber coated centrifuges for filtering concentrated solutions of hydrochloric acid; of "vinyon resin" filter cloths; of Durichlor pumps for sludges; and of glass pumps for acid solutions. All of these have been satisfactory, but the following supplementary list with comments may serve a useful purpose.

Electric motors.-Three-phase totally enclosed motors have given satisfactory service. A high percentage of failures occurred with unprotected motors exposed to acid fumes or spray. Windings made of glass-coated wire reduced the number of failures.

Pipes.-Haveg, Karbate, chemical stoneware (ceramic), porcelain, glass, and Saran pipe gave satisfactory service. In the present plant Haveg pipe was used in most of the installations because it is easily cut and flanged in any desirable length and is a poor conductor of heat. Karbate likewise can be cut and flanged but is more fragile than Haveg. Karbate with graphite base is used where heat transfer is required. Chemical stoneware pipe lines are satisfactory for certain permanent installations but are fragile, quite heavy and difficult to maintain gas-tight at joints. Porcelain pipes are satisfactory but heavy and expensive. Saran pipe has the desirable quality of being fairly flexible, and it can be "welded" without special equipment. However, it is not recommended for continuous use at temperatures above $170^{\circ} \mathrm{F}$. Glass pipe has proved very useful because it enables an operator to follow the progress of reactions. Ordinarily it is not a good conductor of heat, but quite satisfactory heat exchangers can be made of thin-walled glass pipe that is especially made for this purpose.

Valves.-Valves of Haveg, Karbate, stoneware, and porcelain are available and have proved satisfactory. The diaphragms of Haveg and Karbate valves should be made of acid-resistant rubber substitutes.

Pumps.-A Durichlor sludge pump served throughout the entire project for pumping the acid slurry from the digester into the filter press. Examination at the end of 3 years use showed very little acid attack. Glass pumps with graphite packing rings served satisfactorily for pumping all acid solutions. Circulating the solution that was saturated with hydrochloric acid gas and which contained up to $3 \mathrm{lb}$ of aluminum chloride crystals per gallon was the severest test for these pumps. One glass pump was in satisfactory and continuous service for 3 years in such a unit. Stoneware pumps with stuffing boxes were hopelessly unsatisfactory under these conditions. As soon as crystals appeared in the solution, the packing in the 
stuffing boxes disappeared so rapidly that repacking was necessary every hour. In general, pumps with stuffing boxes should be avoided in units where strong hydrochloric acid or suspended crystals are involved.

Circulating fans.-Fans made of metal coated with rubber proved to be the most satisfactory for circulating the gases containing hydrochloric acid. Stoneware also gave satisfactory results, although there was a tendency for the acid to penetrate between metal shafts and ceramic impellers, which finally caused failure.

Heat exchangers. - With one exception, all the heat exchangers were made of Karbate with graphite base as the material through which heat was to be transferred. Thin glass pipe previously mentioned was the one exception. Karbate bayonet heaters were used interchangeably for heating and cooling. After heating a solution for a required time with steam, the steam was replaced with cooling water. This arrangement simplified construction.

\section{Summary}

By referring to the flow sheet, figure 8, the steps of the process can be summarized. Words in italics refer to equipment or stages shown on the flow sheet.

Raw kaolin enters the roaster, then passes to the digester containing hot $\mathrm{HCl}$. From the digester the slurry goes to the filter press where the insoluble matter, consisting largely of $\mathrm{SiO}_{2}$ sludge, is removed and discarded. The acid solution passes to the still $A$ where waste $\mathrm{H}_{2} \mathrm{O}$ is removed, and some dilute hydrochloric acid is thrown back into the " $20 \% \mathrm{HCl}$ storage" reservoir, later to be returned to the digester for decomposition of more kaolin. From still $A$ the concentrated solution goes to the precipitator where $\mathrm{AlCl}_{3} \cdot 6 \mathrm{H}_{2} \mathrm{O}$ is precipitated by coming in contact with $\mathrm{HCl}$ gas. During saturation with $\mathrm{HCl}$ gas the solution is cooled by circulation through cooler $A$. From the precipitator the aluminum chloride, suspended in a solution saturated with $\mathrm{HCl}$, goes to the centrifuge where the aluminum chloride crystals are removed. From the centrifuge the crystals go to the calciner, which converts the chloride to the finished product, $\mathrm{Al}_{2} \mathrm{O}_{3}$, and liberates $\mathrm{HCl}$, part of which condenses in the cooler $B$; the rest is absorbed in the precipitator tower after having been cooled
Stills.-Two stills, one of Haveg the other of Karbate, were in use during the entire project. Both had Karbate bayonet heaters and were about equally satisfactory. Heat losses were greater through the Karbate than through the Haveg.

Waste towers and storage vessels.-Waste towers and storage vessels were made of stoneware.

Gaskets.-Gaskets for flanged pipes were made of Koroseal, (a plasticized polyvinyl chloride). The usual rubber gasket material is unsatisfactory in hydrochloric acid pipe lines because it swells at the flanged junctions and finally nearly seals off small pipes.

Exposed Metal Parts.-In general, exposed metal parts should be painted with acid-resisting paint to prevent corrosion by acid fumes and spray. Small parts may be dipped in hot asphalt. Larger installations can be temporarily protected by painting with such preparations as Bitumastic No. 50 (manufactured by Wailes Dove Hermiston Corporation, Westfield, N. J.).

\section{and Conclusions}

in cooler $B$. $\mathrm{HCl}$ gas for precipitation of $\mathrm{AlCl}_{3} \cdot 6 \mathrm{H}_{2} \mathrm{O}$ from still $B$ is pulled through the cooler $B$, and is circulated through the precipitator by the fan. The bleeder valve serves to regulate recirculation of unabsorbed $\mathrm{HCl}$ and to eliminate air and other gases through the waste tower. The $\mathrm{HCl}$ solutions which are stripped of their gas in still $B$ to supply the precipitator come from three sources, namely, (1) the filtrate from the centrifuge, (2) strong $\mathrm{HCl}$ built up in the process, and (3) makeup acid.

After the filtrate from the crystals of aluminum chloride leaves the centrifuge and has been stripped of its available $\mathrm{HCl}$ gas in still $B$, a part of the residual solution is concentrated to a slurry or cake in the evaporator, the dry or nearly dry residue is ignited in the muffle, the acid is recovered by absorption, and the solids containing the impurities are discarded as waste solids. The remainder of the stripped solution in still $B$ goes back into the " $20 \%$ storage" tank for reuse. The amount of the impure residual solution from stall $B$ that goes to waste solids is greater with clays containing large amounts of impurities than with very pure kaolins, and is the means of elminating impurities from the system. 
All gases emerging from absorption towers pass through the waste tower to catch any unabsorbed gases. The whirling of the centrifuge always liberates some $\mathrm{HCl}$ gas from the saturated solution. This gas likewise is piped to the waste tower.

The process is feasible, but the cost of producing alumina from clay under present conditions is probably 50 percent higher than by the usual Bayer process applied to high-grade bauxite. Installation of efficient heat-exchangers and acid absorption systems will tend to lower costs.

Roasting of kaolin at approximately $700^{\circ} \mathrm{C}$ renders most of the alumina soluble in dilute acid. It has been shown that the solubility of the alumina in the roasted kaolin is definitely related to the amount of original water of constitution that remains. The more original water that remains, the lower the solubility of the alumina.

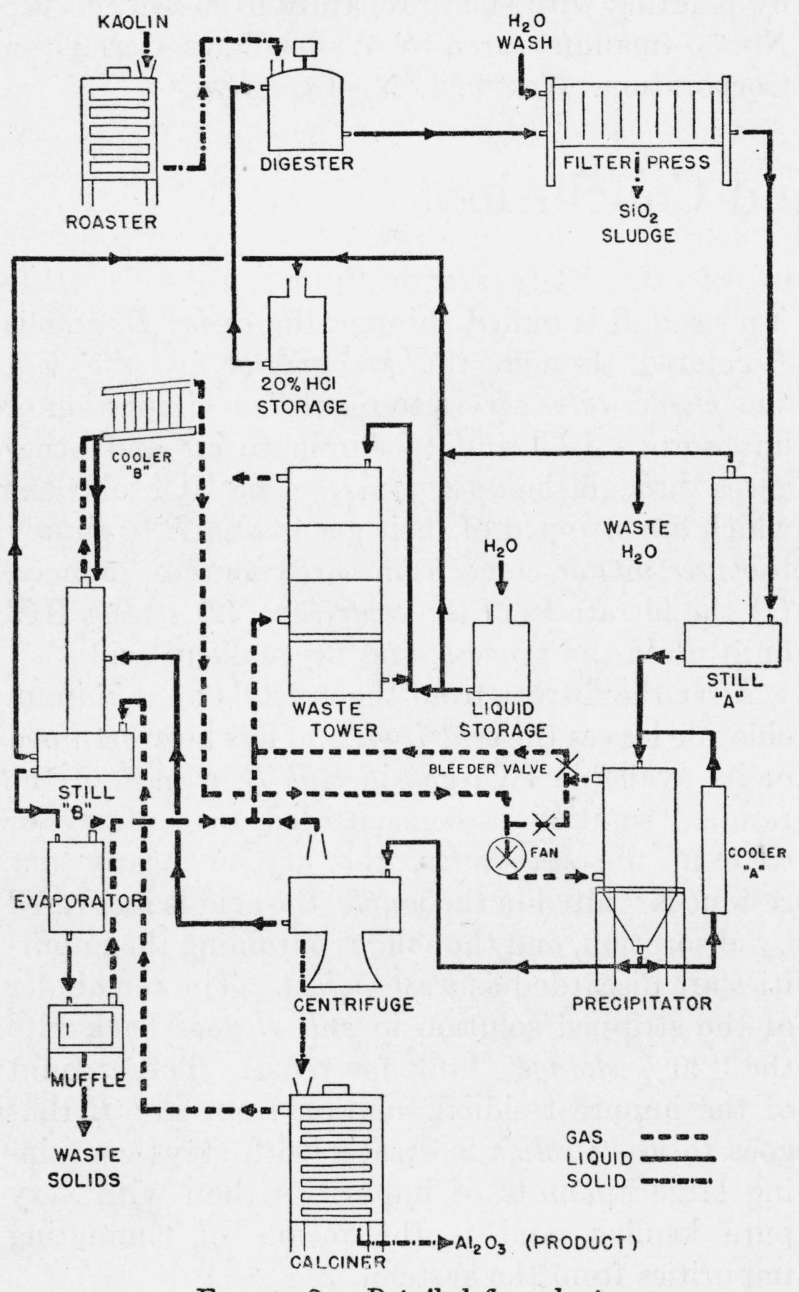

Figure 8.-Detailed flow sheet.
After proper roasting, the constituents of the kaolin act as if they existed as separate compounds. Silica and titania are practically unattacked by dilute hydrochloric acid; alumina and iron oxide are dissolved, and the heat of reaction corresponds closely to that which should be obtained theoretically by dissolving the same quantity of alumina and iron oxide under the same conditions in the absence of the other constituents of the kaolin.

In the studies on distilling hydrochloric acid solutions containing aluminum chloride, it was found that the final distillates always contained less acid than corresponds to constant-boiling hydrochloric acid. This is true whether the initial acid concentration is greater or less than the constant-boiling acid.

It was found that crystals of aluminum chloride hexahydrate, formed in chloride solutions containing much iron, do not contain any appreciable iron within the crystals. It is therefore possible to remove the iron from the surface of the crystals by thorough washing. This affords an easy control of the iron content of the final product.

Either $\alpha$-or $\gamma$-alumina can be produced by this process by proper control of the temperature of ignition of the chloride to the oxide. All the alumina is extremely finely divided. This may be a disadvantage in the reduction to metallic aluminum because of dusting. It has its advantages, however, if the oxide is to be used as a polishing agent for metallographic specimens, as an ingredient of enamels for service at high temperatures, or in other applications where very finely divided and very pure alumina is desirable.

The authors gratefully acknowledge the services of Raymond L. Dodson, who conducted experiments on the decomposition of clays in the early stages of the project; of Wilmer A. Hemminger, who conducted most of the roasting operations in the latter stages of the project; of Willard D. Hubbard, who was responsible for the precipitation cycle and for the calculations on heat transfer and material balances; of George A. Derbyshire, who assisted in the large-scale decomposition of clay near the end of the project; and of Herbert B. Lowey, whose assistance in the mechanical construction of the plant was a notable factor in its successful operation.

Washington, August 20, 1946. 